Thematic

Section

Digital

Transformation,

Intelligent

Manufacturing

and Supply

Chain

Management 4.0

\title{
Highlighting the benefits of Industry 4.0 for production: an agent-based simulation approach
}

\author{
Destacando os benefícios da Indústria 4.0 na produção: \\ uma abordagem de simulação baseada em agentes
}

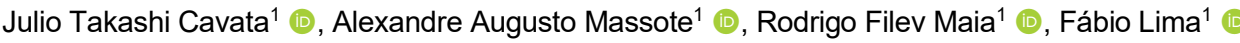 \\ ${ }^{1}$ Centro Universitário FEI, Departamento de Engenharia de Produção, São Bernardo do Campo, SP, Brasil. E-mail: \\ cavata@integradora.com.br; massote@fei.edu.br; rfilev@fei.edu.br; flima@fei.edu.br
}

How to cite: Cavata, J. T., Massote, A. A., Maia, R. F., \& Lima, F. (2020). Highlighting the benefits of Industry 4.0 for production: an agent-based simulation approach. Gestão \& Produção, 27(3), e5619. https://doi.org/10.1590/0104-530X5619-20

\begin{abstract}
Advanced Manufacturing or Industry 4.0 concepts bring new advances and challenges to current industrial processes. Such concepts are not always well understood and their results in terms of production performance may not be clear. This work proposes a comparison between a traditional manufacturing process and an advanced manufacturing process, both modelled by a multiagent society. In the traditional manufacturing simulation, the agents follow the defined times of each process, including the maintenance times. In the advanced manufacturing simulation, the decision about when to stop a piece of equipment for maintenance is defined by the agent according to data received from sensors and the definitions of the process. The results indicate a significant improvement in equipment usage and consequently higher production in the same time interval. The process simulation clearly indicates that the application of advanced manufacturing concepts in industry is relevant in order to increase the efficiency of production processes. Among the main concepts introduced in advanced manufacturing models are the Internet of Things (IoT), Cyber-Physical Systems (CPSs), and Artificial Intelligence (AI). The models generated are computationally simulated using an agent-based simulation method from the software AnyLogic. The results obtained should contribute to encouraging small and medium sized enterprises to adopt the concepts of Industry 4.0 in their businesses.
\end{abstract}

Keywords: Smart manufacturing; Industry 4.0; Cyber Physical Systems; Multi-Agent Systems; Simulation.

Resumo: Os conceitos de Manufatura Avançada ou Indústria 4.0 trazem novos avanços e desafios a serem aplicados nos processos industriais atuais. Tais conceitos nem sempre são bem compreendidos, assim como os seus resultados no desempenho da produção podem não estar claros. Esse trabalho propõe a comparação entre um modelo de manufatura convencional e um modelo de manufatura avançada, ambos modelados por sociedades multiagentes. $\mathrm{Na}$ simulação da manufatura convencional, os agentes seguem os tempos definidos de cada processo, incluindo a manutenção. Na simulação da manufatura avançada, a decisão de quando parar um equipamento para manutenção é definida por um agente de acordo com dados recebidos de sensores e as definições dos processos. Os resultados indicam um aumento significativo na utilização dos equipamentos e como consequência uma maior produção no mesmo intervalo de tempo. A simulação dos processos claramente indica que a aplicação dos . 
conceitos de manufatura avançada na indústria é relevante para aumentar a eficiência dos processos de produção. Dentre os conceitos principais introduzidos no modelo de manufatura avançada estão a Internet das Coisas (IoT), Sistema Físico-Cibernéticos (CPS) e a Inteligência Artificial (IA). Os modelos gerados são computacionalmente simulados usando a simulação baseada em agentes a partir do programa AnyLogic. Os resultados obtidos devem contribuir para incentivar pequenas e médias empresas (SME) a adotarem os conceitos de Indústria 4.0 nos seus negócios.

Palavras-chave: Manufatura avançada; Indústria 4.0; Sistemas Ciber Físico; Sistemas Multi-Agentes; Simulação.

\section{Introduction}

The global technological scenario has been evolving broadly and rapidly with the development of new technologies and the adoption of digital knowledge. This evolution is observed in the routines of human life in several ways, such as society's access to the Internet through smartphones, digital television, automobiles with autonomous driving systems, and integrated information systems, among others.

According to Schwab (2016), this trend is part of the Fourth Industrial Revolution, with technological innovations in several segments, interacting in the physical, digital, and biological domains, and with implications for all sectors of society, such as health, communication, energy, production, agriculture, education, and environment. The physical, digital, and biological domains are deeply related and are grouped into megatrends. Schwab (2016) states that all new developments and technologies have a key characteristic in common: they take advantage of the power of digitization and information technology.

In the industrial and corporate world, the Fourth Industrial Revolution has led to a technological race in various sectors to offer solutions, products, and services, seeking competitive commercial advantages with the promotion of products and services compatible with Industry 4.0 concepts.

In the academy, although previous research related to the Internet of Things (IoT) and Cyber-physical Systems (CPSs) already exists, since 2014 there has been an increase in the volume of academic research related specifically to the theme of Industry 4.0, with growing demand for knowledge of emerging technologies related to this theme (Kang et al., 2016). The academic community is also involved in defining the methods and principles of projects related to Industry 4.0, guiding the groups of pillars that make up the base of Industry 4.0.

Governmental and non-governmental organizations are working to ensure that the development of Industry 4.0 is guided by standards and recommendations such as the report on the Reference Architectural Model Industry 4.0 (RAMI) of the German Association of Engineers and the Technical and Scientific Association for Electrical, Electronic and Information Technology (VDI/VDE, 2015), from the Association of Electrical and Electronics Manufacturers in Germany (ZVEI), the report on recommendations for the implementation of the Industry 4.0 strategic initiative of the National Academy of Science and Engineering from Germany (Acatech, 2013), and the report from the Industrial Internet Consortium (IIC, 2015), a non-profit consortium of partnerships between industry, government, and academia for the industrial Internet in the United States with the Internet reference architecture model and other initiatives in countries where the model is being implemented. 
Within this global context of innovations, manufacturing systems absorb these transformations, and the concept of advanced manufacturing emerges. Advanced manufacturing consists of the evolution of conventional manufacturing with the technological elements of Industry 4.0.

The term "Industry 4.0" mentioned in this work refers to the concepts defined by Acatech (2013) that form the basis for the construction of advanced manufacturing.

Advanced manufacturing provides for a series of advances in the behaviour of its components according to the conditions of the environment. This feature of operation can best be represented in the form of agents. Agents are autonomous entities that have individual operating rules, and the system of interaction of the various agents is called a Multi-Agent System (MAS). For the computational modelling of advanced manufacturing, we start with a literary review of the concepts of MAS and their applicability in agent-based modelling in order to be able to distinguish the behaviour of different agents within a manufacturing environment with the interactions among them.

In the corporate environment of the industrial sector, there is a lack of knowledge and a lack of references to an advanced manufacturing model along with doubts about the level of implementation required and the benefits that can be obtained. In the academic environment, the theme is in the exploratory phase with a gradual increase in research in the sector. The researches comprehensively cover all the components of Industry 4.0 that form advanced manufacturing with works that include concepts from conceptualization to implementation (Hermann et al., 2016). However, there is a gap in the approach of comparative methods and benefits about the new trend of Industry 4.0 and how it can contribute to gains in the production processes of advanced manufacturing.

The aim of this article is to verify, through a comparison between a conventional manufacturing model and an advanced manufacturing model, how the implementation of advanced manufacturing can bring benefits to the companies that adopt it.

The approach consists of presenting the concept of advanced manufacturing and its main implications for the production process through the modelling of an improved conventional production process, with innovations in the control and management systems, making it an advanced production process. Simulation models are based on agents.

\section{Literature review}

\subsection{Analysis}

Initially, an analysis of the scientific literature was performed using the Scopus data base. The proposal was to identify the indicators associated with the keywords "agents", "Industry 4.0", "simulation", and "SMEs" (small and medium enterprises). Figures 1 and 2 show, respectively, the number of publications and the countries of these publications with the combination of keywords "agents" and "Industry 4.0". 


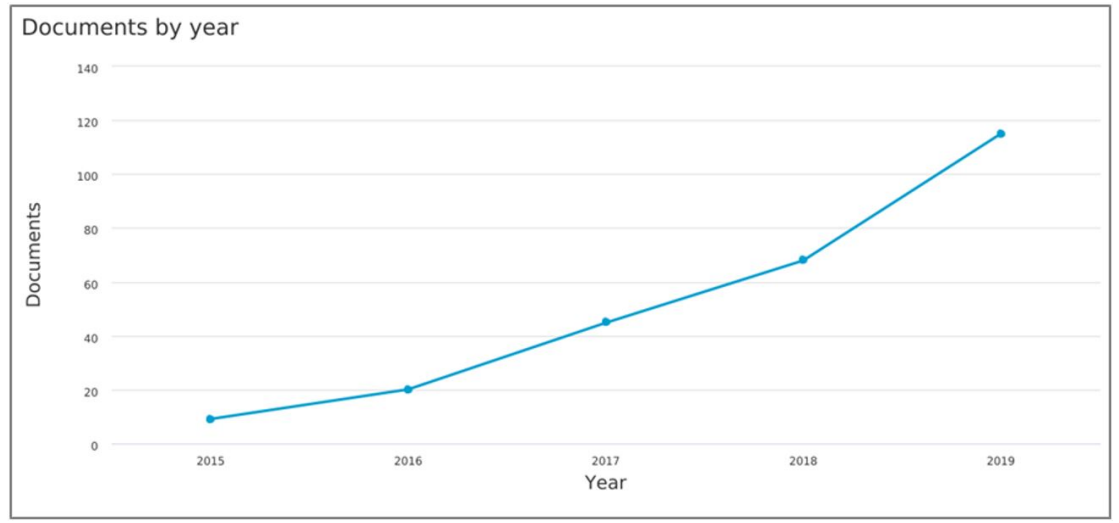

Figure 1. Documents by year in the literature - terms: "agent" and "Industry 4.0".

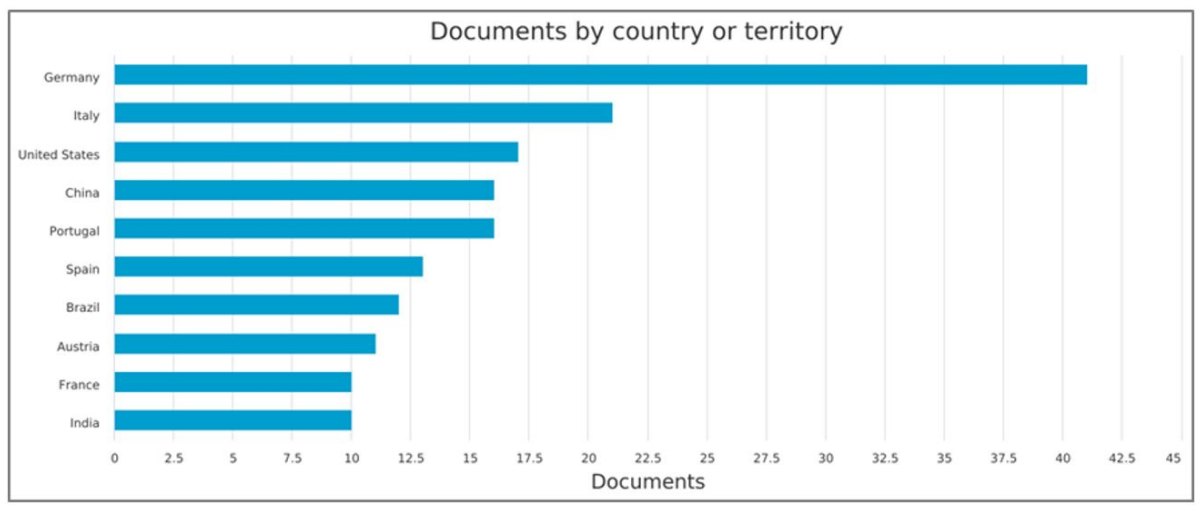

Figure 2. Documents on the topic organized by country - terms: "agent" and "Industry 4.0".

Afterwards, a new analysis was made with the keywords "SME" and "Industry 4.0". Figures 3 and 4 show the number of publications and the countries of those publications, respectively.

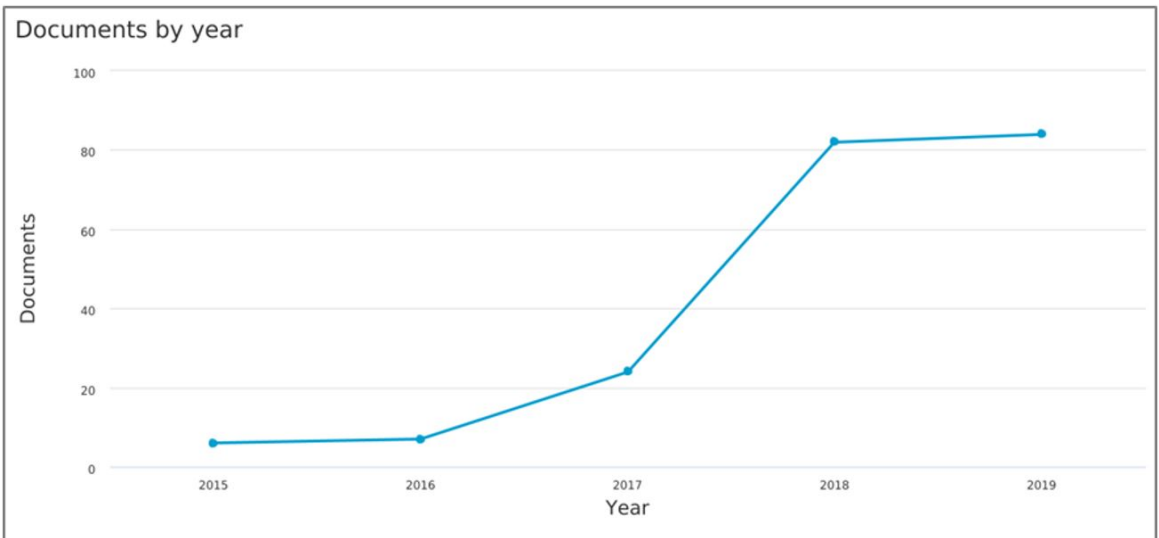

Figure 3. Documents by year in the literature - terms: "SME" and "Industry 4.0". 


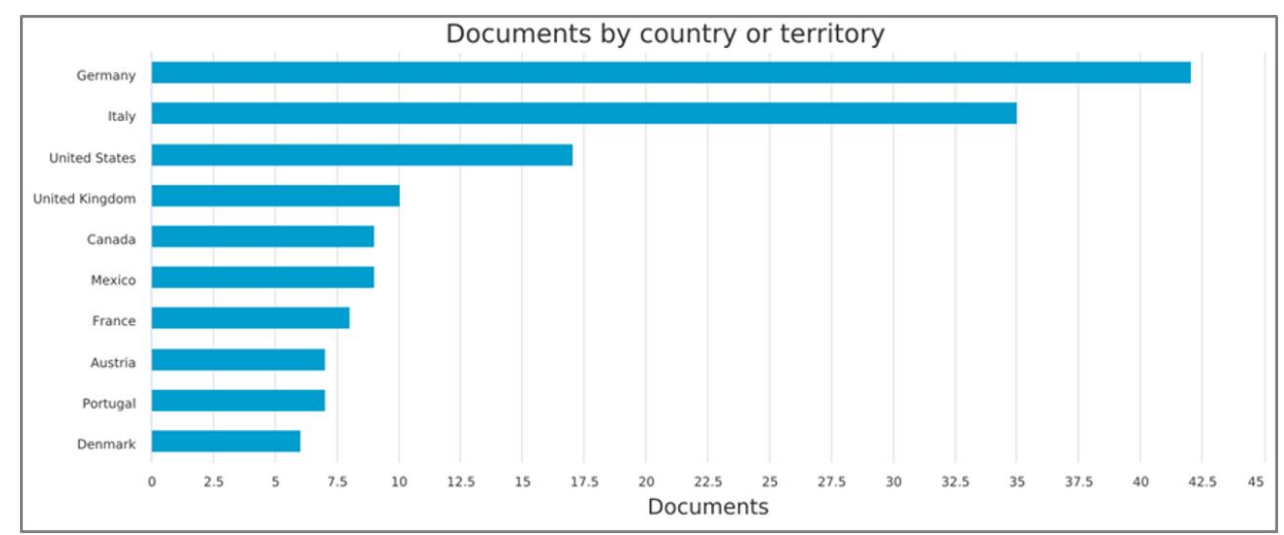

Figure 4. Documents on the topic organized by country - terms: "SME" and "Industry 4.0".

Finally, a final analysis was made combining the keywords "Industry 4.0" and "Agent" and "Simulation". Figures 5 and 6 show, respectively, the number of publications and the countries of those publications.

From the results presented, it is possible to observe the growing number of works related to the use of SMAs and simulations aimed at Industry 4.0. The absence of Brazil in the scope of work aimed at SME and Industry 4.0 is noteworthy, however. This highlights one of the great contributions of this work, which is to present, mainly for SMEs, the benefits of inserting components based on the loT and the consequent implementation of CPSs in traditional manufacturing systems.

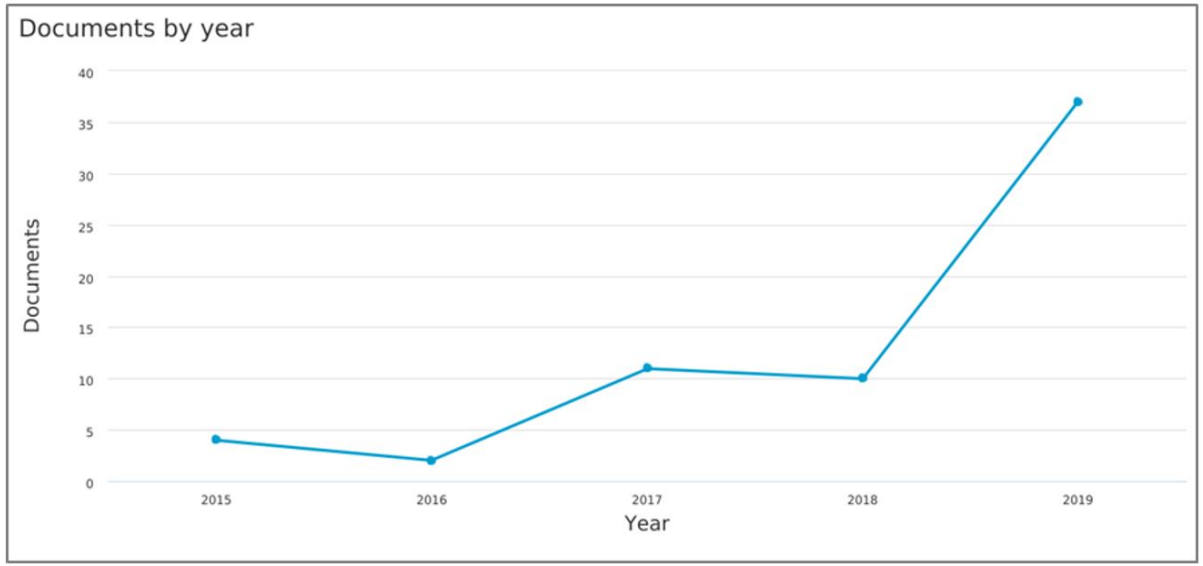

Figure 5. Documents by year in the literature - terms: "agent" and "Industry 4.0", and "simulation". 


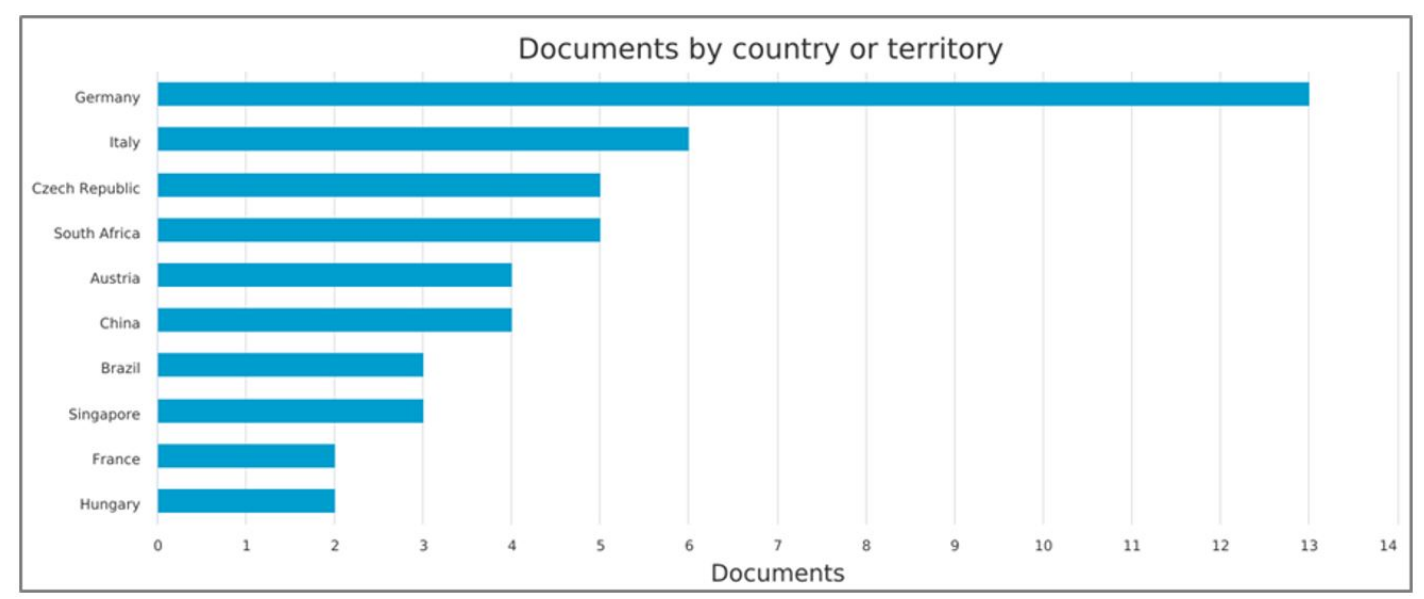

Figure 6. Documents on the topic organized by countries - terms: "agent" and "Industry 4.0", and "simulation".

\subsection{Theoretical background}

Within the industrial area, MASs have been used to model various manufacturing process arrangements. Multi-agent manufacturing processes are characterized by being systems composed of autonomous entities that interact within an environment. Multi-agent technology is widely used in manufacturing processes, system integration, control systems, production planning, and business development, among other applications (Adeyeri et al., 2015).

In Vrba et al. (2011), a PLC (Programmable Logic Controller) control architecture based on the holonic and multi-agent control system is presented.

The work of Leitão et al. (2013) analyses the past, present, and future of the industrial application of agents for industrial control systems.

In a more recent study, Leitão et al. (2016) present the use of agents in CPSs for control and automation and cite real cases of use of agents in advanced production, in an advanced energy network, and in advanced logistics.

Metzger \& Polaków (2011) present the use of MAS in a continuous process automation solution.

Shpilevoy et al. (2013) apply MAS to the modelling of aircraft engine manufacturing production planning, defining agents as production orders, organization, machines, assemblers, products, and operation.

Adeyeri et al. (2015) present a literary review of articles from 2003 to 2014 on the use of agents in manufacturing, specifically in reconfigurable manufacturing systems. The authors propose a structured model of agents for a reconfigurable manufacturing system.

The work of Feng \& Fan (2014) proposes a hybrid model based on Discrete Event Systems (DES) and MAS to study the dynamic planning of multi-skilled labour.

Considering the application of agents in Industry 4.0, the work of Dafflon et al. (2016) proposes the use of agents to optimize the design of drones, using competing engineering concepts.

The production scheduling problem using agents is addressed in Jules \& Saadat (2017). In that work, the authors conclude from the simulations that those involved in manufacturing should express their production goals and preferences regarding with whom they would like to collaborate. 
Considering the use of cyber-physical agents and systems, the work of Novak et al. (2018) performs a hybrid simulation of continuous time systems and SEDs. The proposal mentions applications in Industry 4.0. However, the work is focused on a single piece of equipment and does not include a manufacturing system and its performance.

In Alsina et al. (2014), MAS are used to study preventive maintenance in manufacturing systems.

Kadera \& Novák (2015) assess the performance of MAS when applied to manufacturing systems. The approach is not the evaluation of the production itself, but the evaluation of the MAS.

In Büth et al. (2017), a methodology for the development of simulation models for SED based on SMA is presented.

Scholz et al. (2017) propose an integration of an SMA with an DES on the shop floor, highlighting the need to use SMA models for advanced manufacturing systems.

To conclude the literature review, although discussions on Industry 4.0 are increasing worldwide, there is still a research gap regarding the effective benefits that this concept can bring in comparison with traditional production systems. This is the main contribution of this article, using modelling and simulation based on an MAS for this comparison. Moreover, it is highlighted that such a comparison can mainly encourage small and medium-sized companies to adhere to the concepts of Industry 4.0.

\section{Methodology}

This methodological work is quantitative and exploratory. The methodological approach adopted is modelling and simulation, quantitatively comparing the results obtained from the computational simulation of advanced manufacturing with the results of the simulation of conventional manufacturing.

In this computational modelling and simulation work, conventional and advanced manufacturing models were developed in the computer simulation program AnyLogic to analyse the indicators obtained from the simulation and evaluate the advantages and disadvantages of advanced manufacturing.

\section{Chosen manufacturing system}

The manufacturing system scenario defined for modelling consists of a process commonly used in metallurgical companies that manufacture welded subsets for the automotive sector.

The conventional process of manufacturing welded subsets consists of production and storage machines and equipment that will be part of the production flow from the receipt of raw materials to the final shipment. The typical production flow structure is shown in Figure 7 and is divided into the following production areas:

1) Receipt of materials;

2) Cutting steel coils;

3) Stamping for cutting and forming parts of the subset;

4) Welding the parts to form the subset;

5) Quality control;

6) Packaging and storage of finished product; 


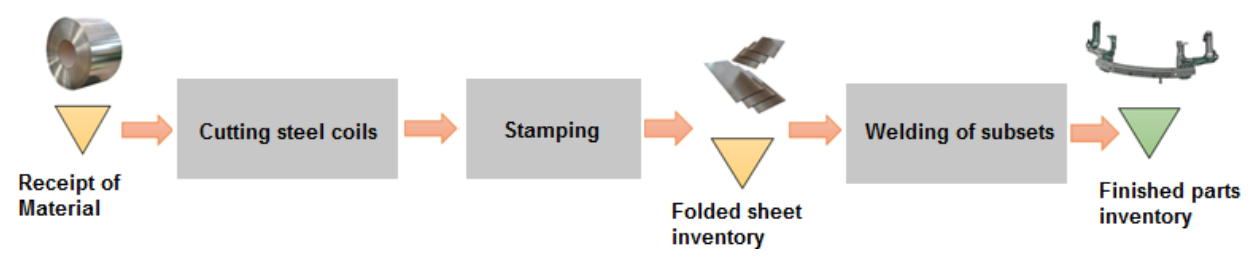

Figure 7. Manufacturing flow of welded subset.

The material-receiving area stores basic raw materials such as steel coils and steel plates as well as accessories such as screws, welding inputs, and other items that will compose the subset.

The cutting area refers to the machinery for cutting steel coils into steel plates or dividing the coils received from the steel mill into coils with smaller strips to feed presses.

The stamping area performs the cutting and shaping of steel plates and steel strips in coils forming the stamped parts that form the subset.

The welding area groups the stamped parts together, forming the welded subset. The stamped parts are grouped on fixing devices so that the parts can be welded using welding robots. The quality of the product is verified through templates that are used for sample verification. At the end, the finished product is packed and stored in the shipment to be sent to the contracting company.

In addition to the production areas, there are intermediate storage areas for balancing production, storing stamped parts, and storing finished products.

Among the areas mentioned, stamping and welding are the main areas with greater complexity of operation. In the stamping area, it is necessary to change the tool for each batch of parts produced, and in the welding area, the quality of the weld and the dimensions of the set are constantly checked.

The stamping area model is formed by a group of four presses that cut and draw the steel sheet to form the parts. The weld area model is formed by two robotic cells to form the welded subset from the stamped parts. The model considers that each subset will consist of eight types of stamped parts. The presses can stamp any of the parts using the corresponding tooling. The welding cells are independent and weld the complete subset.

The production process in stamping is supported by the tooling team for the preparation of tooling in the press and adjustments during production. All areas are supported by the maintenance team for the repair of machines and welding cells and for preventive maintenance.

\section{Agent-based modelling}

Conventional manufacturing and advanced manufacturing can be represented by the agent-based modelling method. Next, the structure of the agents that make up the conventional manufacturing model and the changes in the model to represent advanced manufacturing are defined. Modelling based on agents is oriented to the individual or to the agent, defining their individual behaviour in reaction to the events generated by the operating environment. 


\subsection{Structure of agents: conventional manufacturing}

Conventional manufacturing is modelled in the form of agents that interact with each other and with the environment. Agents can be categorized as "reactive learning" when reacting to environmental conditions in conventional manufacturing (Balaji \& Srinivasan, 2010). The following agents are considered within the manufacturing environment:

- Press agent - represents the stamping machine: cutting and drawing;

- Tool agent - represents the tooling for stamping;

- Tooling agent - represents the technician who performs the preparation and exchange of tools and the maintenance of their state of functioning;

- Weld agent - represents the robotized welding cell for the formation of the welded subset;

- Maintenance agent - represents the technician who performs the maintenance of the machines.

\subsubsection{Press agent}

The agent called "press" defines the press-type machine that performs the cutting and shaping operation of the steel sheet to form the stamped part. The press can basically be in two different states: "idle" and "in operation". In the "idle" state, the machine is stopped and is waiting for a production order. In the "in operation" state, the machine is in production of the batch of parts referring to the production order received. However, on receiving the production order, the machine needs to be prepared for the production of the product selected by the production order. This condition is represented by the state "in preparation". After the preparation is finished, the machine goes into the operating state.

The machine in operation may suffer a malfunction that causes a production stop. The malfunction can occur due to several causes, such as the wear of some component, misadjustment of the machine settings, an error in the operation, the product being out of specification, and external causes such as power failure, among others. In this situation, the machine stops producing and goes into to the "corrective maintenance" state.

The machine can also have scheduled stops to perform preventive maintenance from an action plan with defined tasks, such as changing worn components, cleaning filters, retightening screws, and other actions recommended by the manufacturer. In this situation, the machine goes into the "preventive maintenance" state. Preventive maintenance, being scheduled, takes place when the machine returns to the idle condition.

Other operating conditions must also be considered, such as the lack of availability of the tooling when requested to prepare for a new production order. It may happen that the machine had had a problem and, when the tooling or preparation for new steel coils is changed, flaws in the machine are discovered, requiring corrective maintenance during preparation.

During the operating state, a quality check must be carried out on a sample for each certain number of parts produced or for a certain period of operation. If this inspection reveals a product failure, because it is out of specification, the operation must be 
stopped and an adjustment state is started so that the tool is corrected and afterwards the press returns to operation.

At the end of the production of the batch of parts defined in the production order, there is a new intervention by the tooling to remove the used tooling from the press.

In order to reflect the conditions mentioned in the model, the press is represented by two distinct agents: one agent represents the press as a machine and another agent represents the tools. Figure 8 shows the sequence of states of the press agent.

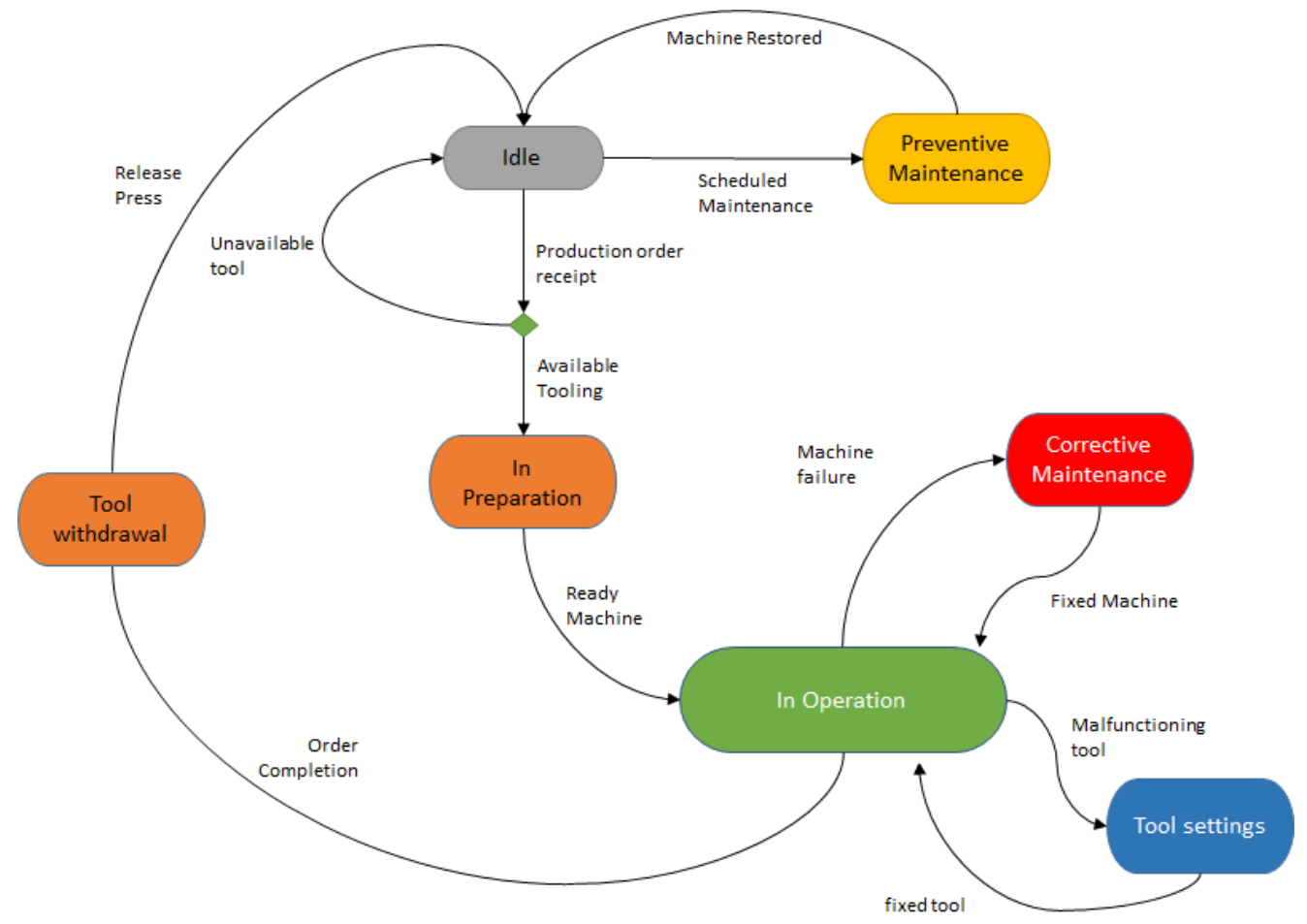

Figure 8. State diagram of the press agent.

\subsubsection{Tool agent}

The agent called "tool" defines the stamping tooling to be used in the press for the cutting and drawing operation of the part to be produced. Each part to be produced has its specific tooling. The tooling can be in an "idle" or an "operating" state. In the "idle" state, the tooling may be stored, waiting for the next request to use the tool, or it may be under repair and preventive maintenance. In the "in operation" state, it will be mounted on the machine producing the parts of the production order. Figure 9 shows the sequence of states of the tooling agent. 


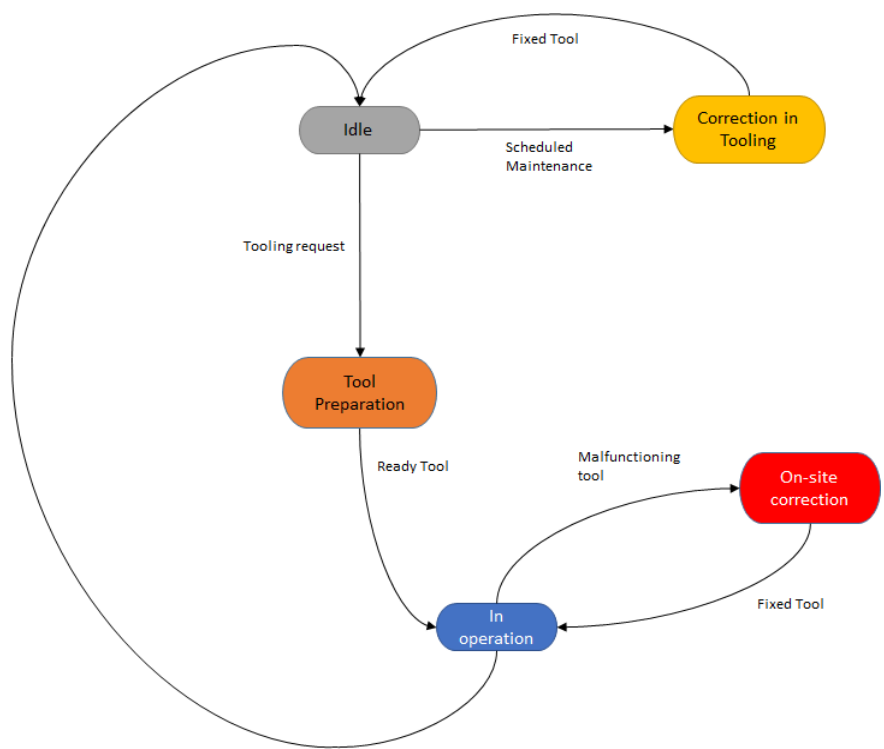

Figure 9. State diagram of the tool agent.

\subsubsection{Tooling agent}

The agent called "tooling" is composed of technicians who prepare the machine for the execution of the production order. Technicians can be in "idle" or "in service" state. In the "idle" state, technicians are available in the tooling area. In the "in service" state, several activities can be performed, namely preparing the tool in the press, adjusting the tool in operation in the press, removing the tool from the press, and preventive maintenance of tools that are not being used. Figure 10 shows the sequence of states of the tooling agent.

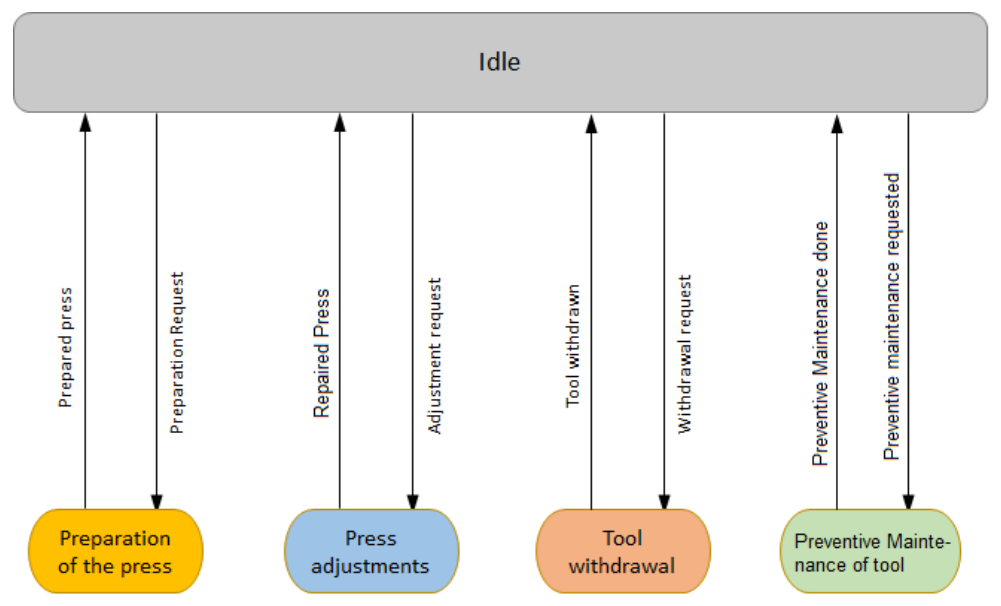

Figure 10. State diagram of the tooling agent. 
The welding cell may stop due to problems or failures that require intervention by the maintenance team to carry out repairs and adjustments. Preventive maintenance is periodically programmed based on an action plan with tasks such as changing worn components, checking the robot and welding machine, cleaning the area, retightening screws, and other actions recommended by the manufacturer. In this situation, the machine goes into the "preventive" state. Figure 11 shows the sequence of states of the weld agent.

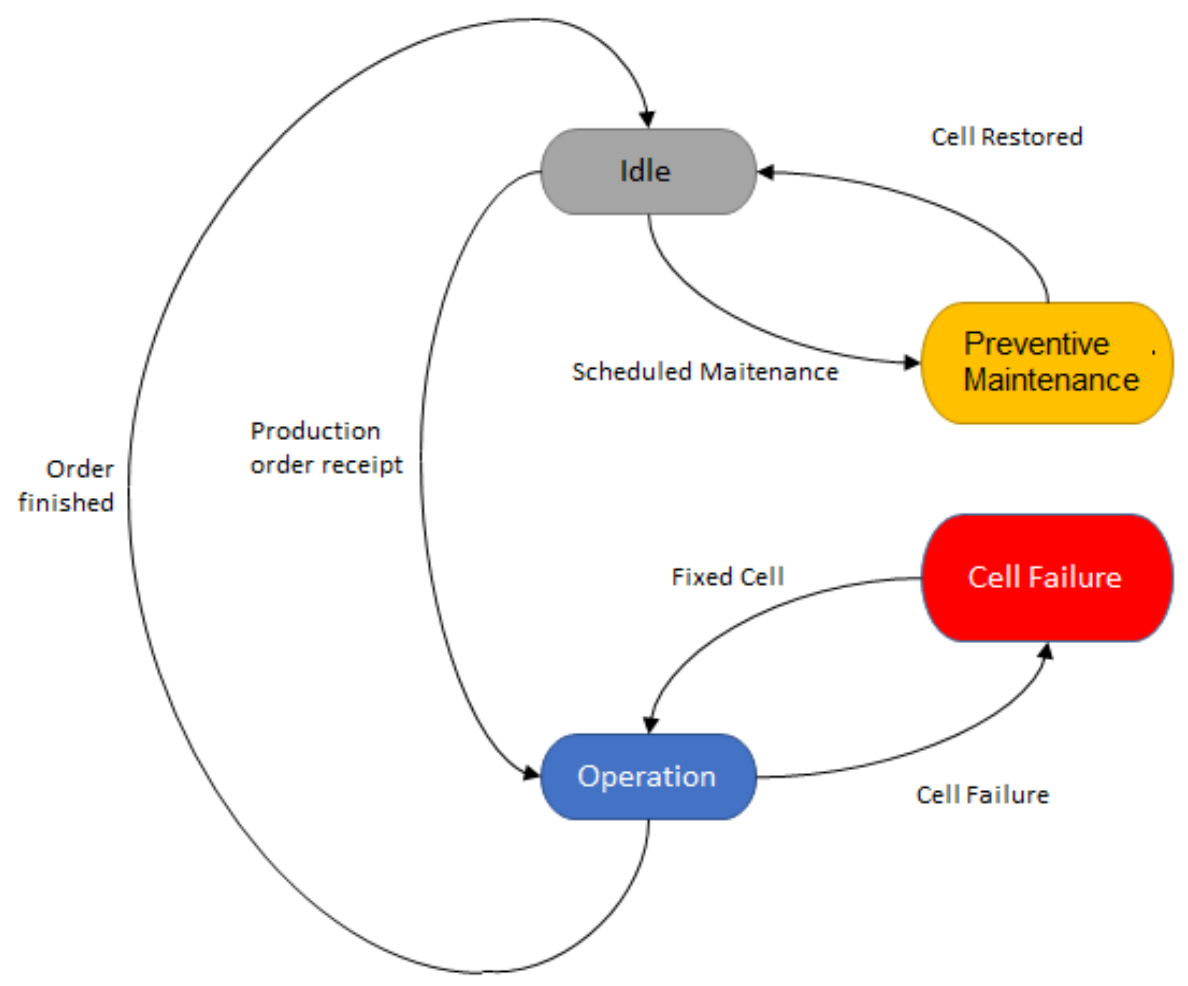

Figure 11. State diagram of the weld agent.

\subsubsection{Maintenance agent}

The agent called "maintenance" is composed of technicians who perform the maintenance of presses and weld cells. Technicians can be in an "idle" or an "in service" state. In the "idle" state, technicians are available in the maintenance area. In the "in service" state, they can be correcting faults in a press or a weld cell, carrying out the necessary repairs, or performing preventive maintenance on the machines. Figure 12 shows the sequence of states of the maintenance agent. 


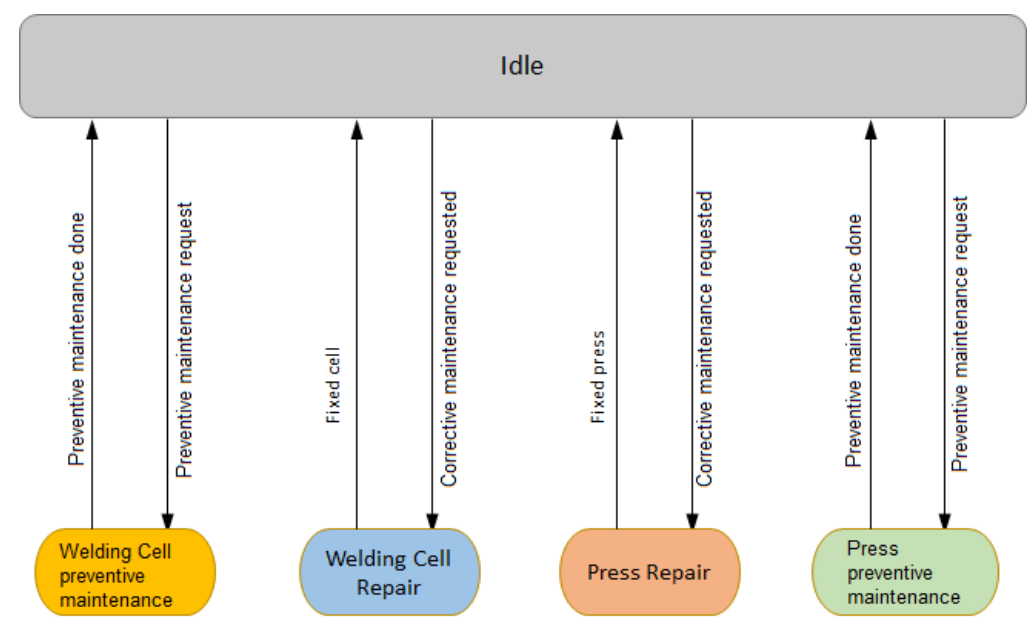

Figure 12. State diagram of the maintenance agent.

\subsection{Structure of agents: advanced manufacturing}

In this discussion, the agents defined in the modelling of conventional manufacturing, are considered, with the incorporation of advanced manufacturing functionalities such as the loT and the CPSs in their environments and behaviours. The presses, as well as the machines, will be constantly monitored through sensors connected by a communication network to a data server and their digital models will be constantly updated. The collected data will be processed and thus their behaviour can be predicted through machine learning. In this way, it is possible to predict when a preventive maintenance should be carried out in advance, allowing the advance purchase of parts and pieces that will be needed at the time of the maintenance stoppage. With the monitoring of the press structure, it is possible to evaluate problems in the columns, lubrication, warping, levelling, vibrations, and other factors that can lead to damage that causes stoppage.

The stamping tooling will also be monitored through the loT and CPS using sensors installed in the tool that will digitize its behaviour to the control system of the press. Through the data obtained by the installed sensors and their behaviour monitored during the operation, it is possible to predict the wear that will occur, forming a trend of deviation from the dimensions of the produced part. Through video cameras on the parts produced, it may be possible to read the main dimensions of the part. Other sensors should be used to assess damage to tool structures such as cracks or warping.

The digital control system of the robotized welding cell, which is constantly monitored, provides information about the quality of the weld, predicts a lack of inputs, and predicts the behaviour of the robot and the welding machine to correct problems optimally. There is also quality control of the welded set to determine deviation trends. Thus, the system can correct itself without the need to stop the cell.

Maintenance and tooling technicians will be activated with greater speed once they are connected to the information system. Thus, the diagnosis of problems will be defined more accurately and quickly by an Al system based on the historical data stored in the system. An augmented reality system makes the execution of jobs faster and more deterministic through a visualization system that informs the entire work sequence to be performed by the operator based on the diagnosis of the Artificial Intelligence system. 
These proposed implementations follow the theory of CPSs of the $5 \mathrm{C}$ architecture of Lee et al. (2015) and uses some of the features described in the ontology presented by Trappey et al. (2016).

\subsubsection{Advanced press}

An advanced press, when receiving the production order, can automatically verify whether the tooling for that product is available or not. This is because the resource planning system for production (ERP) has already verified the condition of the necessary tool, whether it is available, and the operational condition of how many cycles it can still support. Thus, planning can assume that it will have no problems during the operation for that planned batch in the production order.

During operation, the press will be monitored by a communication network and its data will be stored on a data server so that all small variations can be captured and analysed. In this control situation, it is possible to detect a tendency of a problem and act in three different ways: in the first mode, there is an interruption of operation with an immediate maintenance call to correct the problem in the shortest possible time to restore production; in the second mode, auto correction takes place to enable the press to be adjusted without interference by the operator or maintenance, restoring production; or, in the third mode, it is determined that it is possible to finish the batch of parts satisfactorily without a malfunction occurring and thus to continue the operation to the end of the production order. At the end of the production order, the actions to be taken before the start of the next production order are defined.

\subsubsection{Advanced tooling}

During operation, the tool will be monitored by a communication network and its data will be stored on a data server so that all small variations can be captured and analysed. In this control situation, the trend of a problem can be detected and acted on in three different ways: in the first mode, there is an interruption of the operation with an immediate call from the tooling to correct the problem in the shortest possible time to restore production; in the second mode, self-correction occurs to adjust it without interference from the operator or tooling, reestablishing production; or in the third mode, it is determined that it is possible to finish the batch of parts satisfactorily without a major breakdown and thus to continue the operation to the end of the production order. At the end of the production order, the actions to be taken before the start of the next order are defined.

\subsubsection{Advanced welding cell}

The advanced welding cell will be connected to the ERP management system so that it is ready when the batch of parts is available for production. It will define, based on the model, the appropriate time for automatic repair actions based on the press operation information. It will also determine related activities such as correcting trajectories and cleaning the welding system, which can be carried out in this interval without impairing the production flow. 
During operation, the weld cell will be monitored and its data will be stored on the data server so that all small variations can be captured and analysed for correction in the shortest possible time.

\subsubsection{Advanced preparation and maintenance services}

Preparation and maintenance services can be enhanced with artificial intelligence processes through machine learning, mapping the history of causes and effects of behavioural conditions. In this way, a more accurate and quick diagnosis is possible, reducing the intervention time on the machine and reducing the downtime. With additive manufacturing, one of the enabling technologies of advanced manufacturing, spare parts for damaged parts of machines and equipment can be manufactured in less time than with conventional machining modes, reducing intervention and machine downtime.

\section{Agent-based simulation}

\subsection{Conventional manufacturing}

In the computational simulation model of the AnyLogic software, seven agents that form the main executable model are represented. They are:

- "Press" agent - represents the press that performs the operation of forming the parts;

- "Tool" agent - represents the tool that will be used in the press to perform the conformation of a specific part;

- "Tooling" agent - represents the team of toolmakers who carry out the preparation and adjustment of the tool in the press;

- "Weld" agent - represents the robotized welding cell that performs the welding operation of the subset from the stamped parts;

- "Maintenance" agent - represents the machine maintenance team that performs corrective and preventive maintenance of presses and welding cells;

- "Orders" agent - represents production orders that are generated by the system for the execution of production operations;

- "Main" agent - the main program that forms the general structure of the simulated model.

The data used in the simulation, referring to each of the agents, are typical industrial data for the operation of presses and welding systems. The most important thing in this approach is that data such as the cycle time, among others, that are presented for conventional manufacturing are also maintained in the advanced manufacturing model, ensuring that the evaluation of the gains obtained is carried out properly.

\subsection{Computer model of the press agent}

The press agent defines the autonomous press-type machine that performs the product-forming function and is represented in the state diagram in Figure 13. 


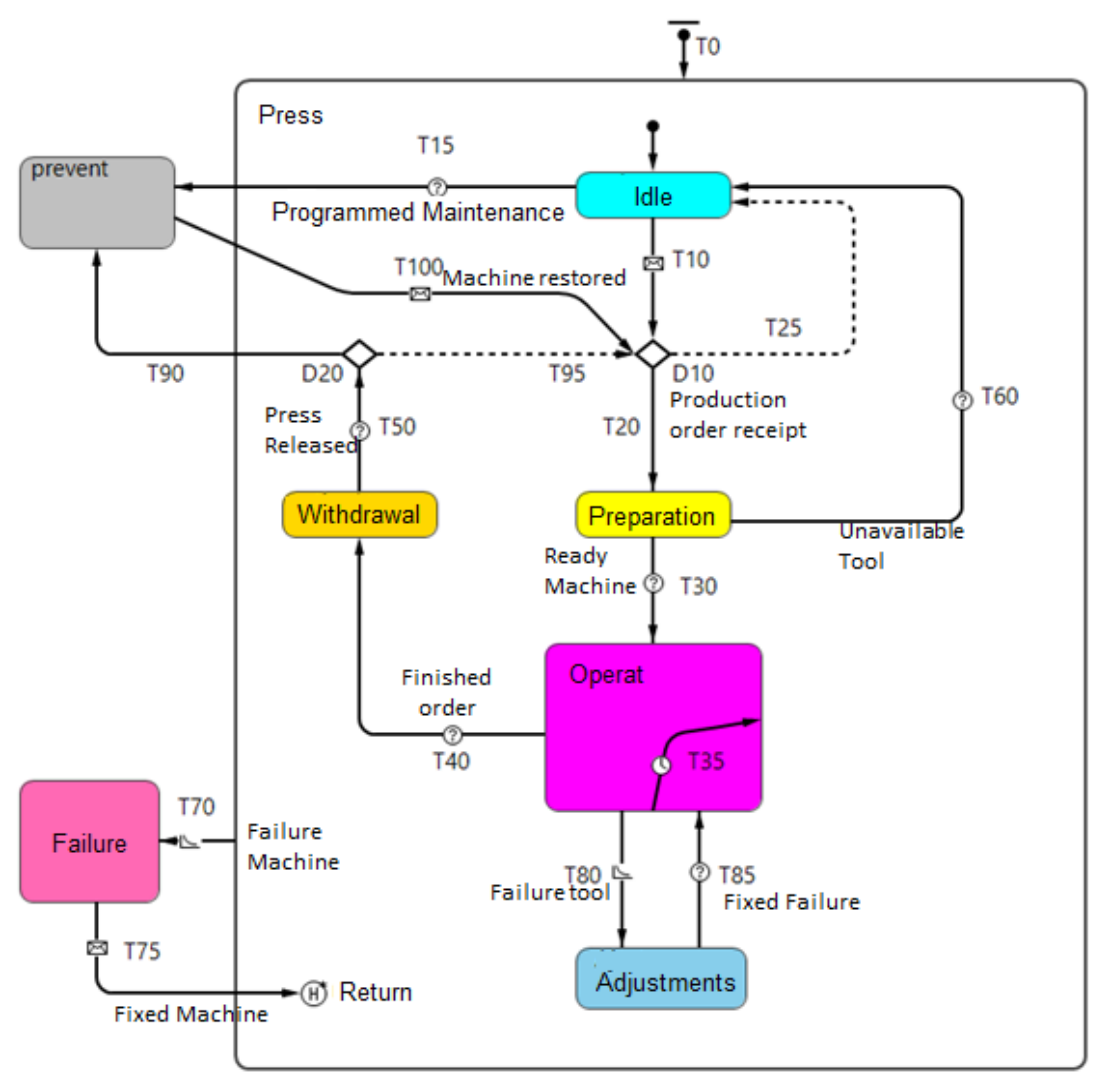

Figure 13. State diagram of the press agent.

At decision point D10, in the state diagram, a check is made on whether there is a production order in the queue. If there is a production order, the press goes through the T20 transition and enters the "preparation" state to wait for the "tooling" agent to prepare the press for the product defined in the production order.

The preparation has two termination conditions: first, successful completion of the preparation (transition T30), and second, unavailability of the tool (transition T60) due to it being used in another press or being in the preventive maintenance state.

In the operating state called "operat" in the diagram, the press performs the forming operation represented by the internal transition T35 that occurs with each part executed. At the end of production of the number of parts defined in the production order, the transition T40 occurs, which leads to the disassembly state of the press tooling (the "withdrawal" state). In this state of "operat", deviations in the quality of the product can occur, leading to a need for adjustments in the tooling (transition T80), which leads to the state "adjustments".

At any time during operation of the press, a failure can occur in it that generates a T70 transition that leads to the "failure" state.

At the end of disassembly of the tooling in the "withdrawal" state, at decision point $\mathrm{D} 20$, the deadline for preventive maintenance of the press is verified. If the deadline has passed, the T90 transition is activated and the model enters the "prevent" state for the performance of preventive maintenance.

The "press" agent has the main parameters defined in Table 1. 
Table 1. Press agent parameters.

\begin{tabular}{ccc}
\hline Parameter & Transition & Value \\
\hline Press cycle time for one-piece forming & T35 & 15 seconds \\
\hline Press failure rate: maintenance intervention & T70 & 15 failures/month \\
\hline Machine MTBF (mean time between failures) & - & 2 days \\
\hline Deviation rate in product quality & T80 & 4 interventions/day \\
\hline Preventive maintenance lead time & T15 and T90 & 120 days
\end{tabular}

The occurrences of machine failures are sporadic and their periodicity is based on an exponential distribution of an average of known occurrences from historical data collected (MTBF - mean time between failures) (Borshchev, 2014).

\subsubsection{Computational model of the agent "Tool"}

The "tool" agent defines the tooling used to make a given product as an autonomous agent according to the state diagram in Figure 14.

The tool is allocated to a particular press according to the product to be produced. The tool is allocated in the T10 transition from the request for preparation of the press by the tooling team.

The tool undergoes preventive maintenance at each defined interval to correct certain wear and tear that may occur in the tooling (transition T30). This time is specified in Table 2.

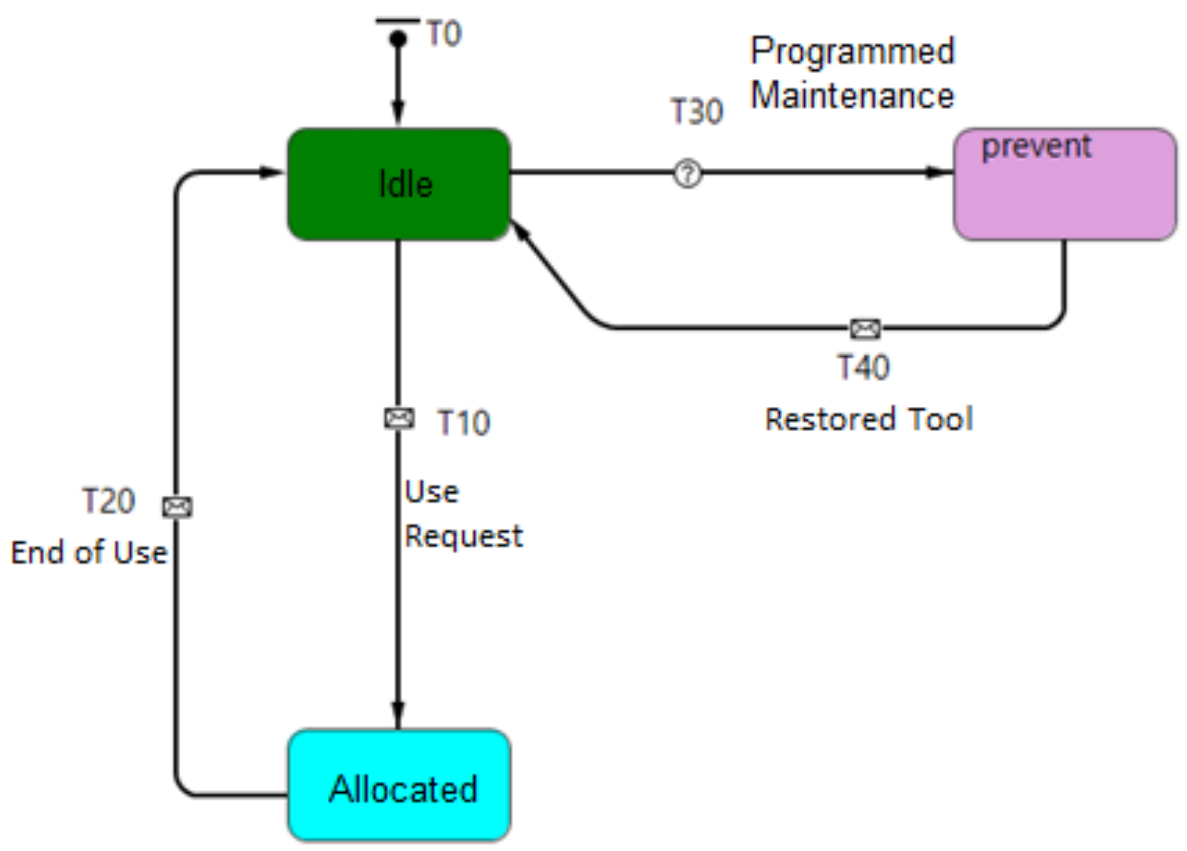

Figure 14. State diagram of the Tool agent. 
Table 2. Tool agent parameters.

\begin{tabular}{ccc}
\hline Parameter & Transition & Value \\
\hline $\begin{array}{c}\text { Period of execution of preventive maintenance to review } \\
\text { the status of the tooling }\end{array}$ & T30 & 30 days \\
\hline
\end{tabular}

\subsubsection{Computational model of the "Tooling" agent}

The "tooling" agent defines the team of toolmakers who carry out the preparation of the press tooling for the conformation of a certain product, removal of the tooling, tooling adjustments in the press, and preventive maintenance of the tooling and is represented in the state diagram in Figure 15.

At decision points $D 10$ and $D 15$, the queue of press preparation requests is checked and the tooling is free for use. At decision point D20, the queue of requests for tooling adjustments in the press is verified due to quality deviations. At decision point $D 30$, the queue for requests to remove tooling from the press is checked. At decision point D40, the queue of requests for preventive maintenance of the tooling is checked.

The "tooling" agent has specific times for the execution of each activity defined in Table 3.

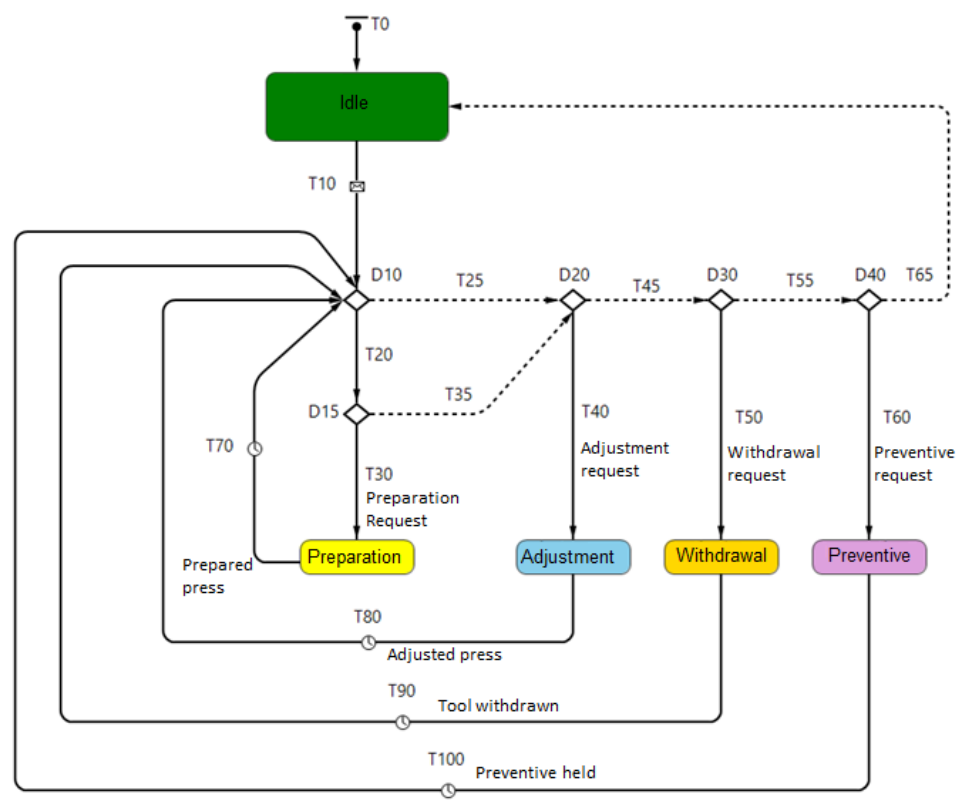

Figure 15. State diagram of the Tooling agent.

Table 3. Tooling agent parameters.

\begin{tabular}{ccc}
\hline Parameter & Transition & Value \\
\hline Tool preparation time in the press & T70 & 60 minutes \\
\hline Adjustment time for product quality correction & T80 & 15 minutes \\
\hline Time to remove the tooling from the press & T90 & 30 minutes \\
\hline Time to perform preventive maintenance & T100 & 4 hours \\
\hline
\end{tabular}


To represent the variations that may occur in the execution times, a triangular distribution with a minimum value of $50 \%$ of the nominal value and a maximum value of $150 \%$ of the nominal value was considered. Times may vary depending on the type of fault to be corrected and the tool model to be changed. In this study, a statistical distribution was adopted to represent these variations. The type of distribution does not affect the results as the same data and distributions are applied equally across all compared models.

\subsubsection{Computational model of the "Weld" agent}

The "weld" agent defines the robotic welding cell that performs the assembly and welding functions of the set of stamped parts and is represented in the state diagram in Figure 16.

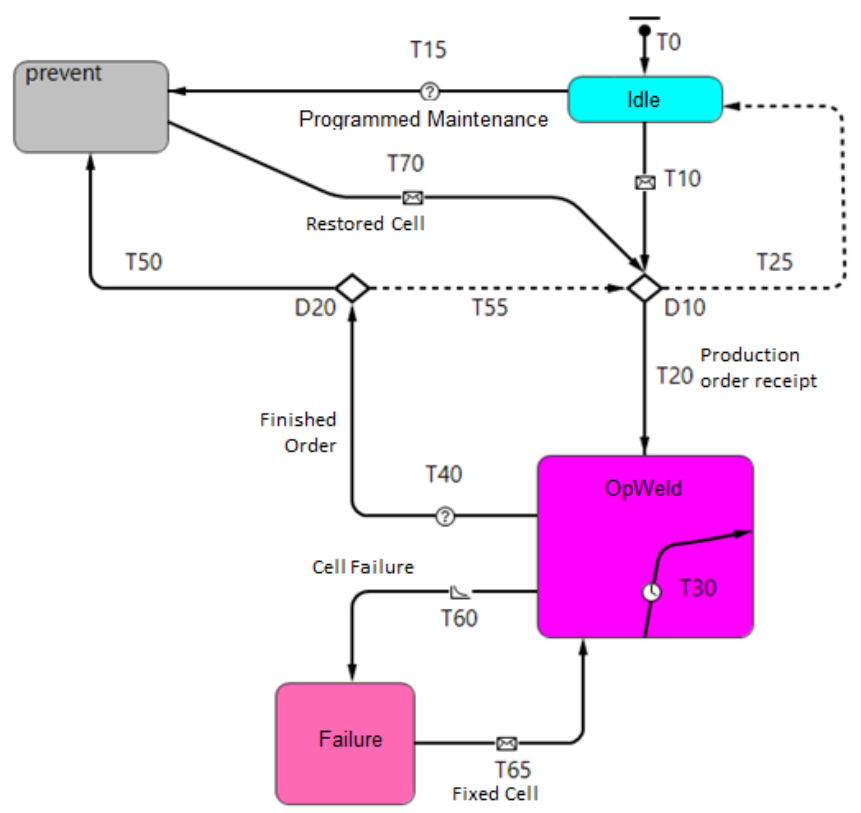

Figure 16. State diagram of the Weld agent.

At decision point D10 of the state diagram, a check is made to verify whether there is at least one batch of each stamped component in the queue to form the weld set. If the quantity is sufficient to form the set, the weld cell goes through the T20 transition, enters the "opweld" state, and welds the batch of sets.

At any time of the welding operation, a fault may occur that generates a T60 transition that leads to the "failure" state.

At the end of the number of sets defined in the production order, the T40 transition to decision point D20 takes place and the deadline for preventive maintenance of the cell is verified. If the deadline has passed, the T50 transition is activated and enters the "prevent" state to carry out preventive maintenance.

The "weld" agent has the main parameters defined in Table 4. 
Table 4. Weld agent parameters.

\begin{tabular}{ccc}
\hline Parameter & Transition & Value \\
\hline Cycle time for welding an assembly & T30 & 120 seconds \\
\hline $\begin{array}{c}\text { Rate of failure interventions or adjustments in the } \\
\text { weld cell or exchange of electrodes }\end{array}$ & T60 & 6 interventions/day \\
\hline Preventive maintenance lead time & T15 and T50 & 120 days \\
\hline
\end{tabular}

\subsubsection{Computational Model of the "Maintenance" agent}

The "maintenance" agent defines the maintenance team for machines and equipment that perform corrective and preventive maintenance of presses and welding cells and is represented in the state diagram in Figure 17.

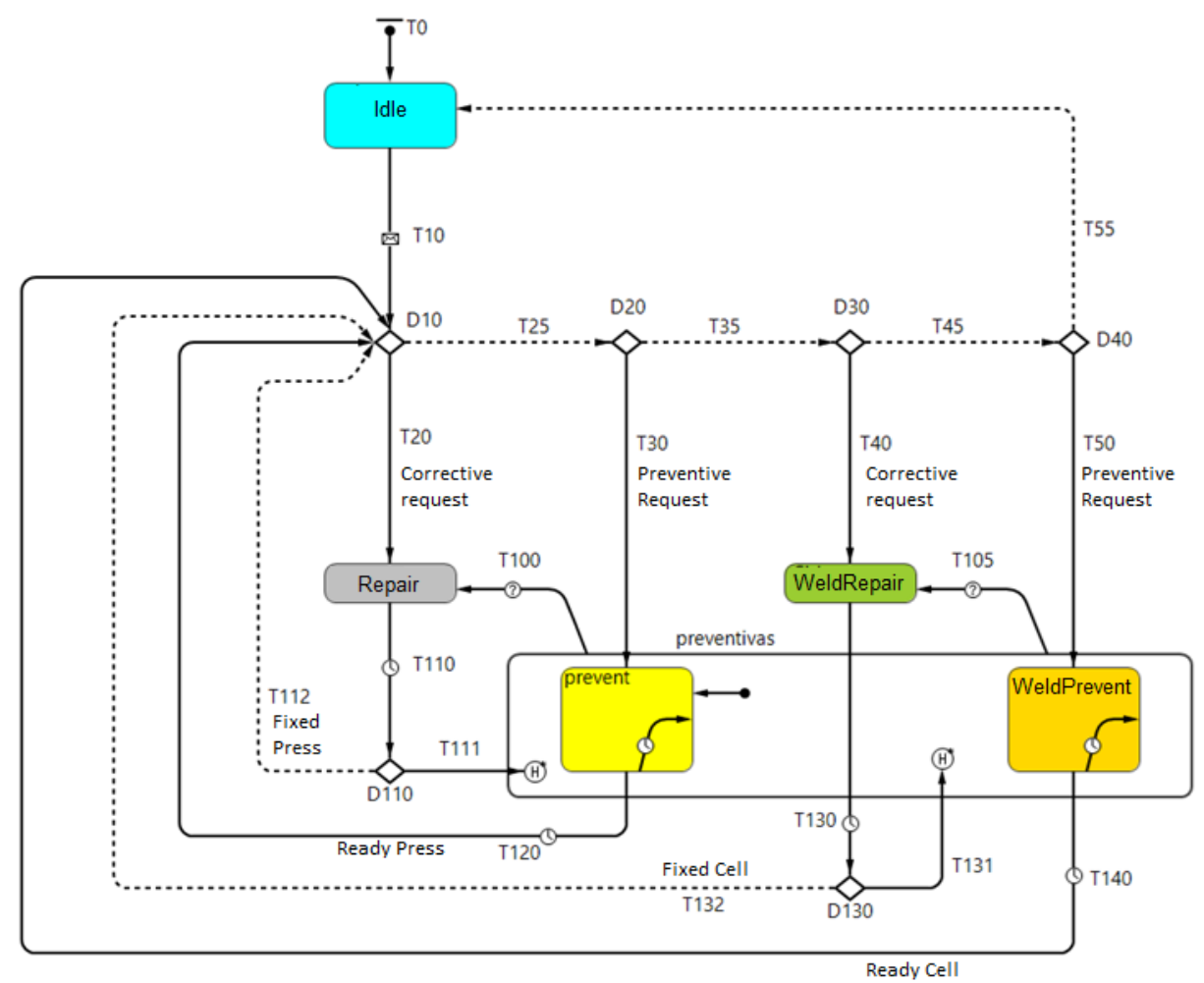

Figure 17. State diagram of the maintenance agent.

At decision points D10, D20, D30, and D40, the queue of requests for press repair, preventive press maintenance, weld cell repair, and preventive weld cell maintenance, respectively, is checked. Corrective maintenance operations take priority over preventive maintenance and thus the T100 and T101 transitions occur when there is request for a repair to be performed on the presses or robotic cells.

The "maintenance" agent has specific times for performing corrective and preventive maintenance, defined in Table 5. 
Table 5. Maintenance agent parameters.

\begin{tabular}{ccc}
\hline Parameters & Transition & Value \\
\hline Corrective maintenance time for the press & T110 & 30 minutes \\
\hline Preventive maintenance time for the press & T120 & 24 hours \\
\hline Corrective maintenance time for the welding cell & T130 & 30 minutes \\
\hline Preventive maintenance time for the welding cell & T140 & 24 hours \\
\hline
\end{tabular}

To represent the variations that may occur in the execution times, a triangular distribution with a minimum value of $50 \%$ of the nominal value and a maximum value of $150 \%$ of the nominal value is considered. Times may vary depending on the type of fault to be corrected. In this study, a statistical distribution was adopted to represent these variations. The type of distribution does not affect the results as the same data and distributions are applied equally across all compared models.

\subsubsection{Computational model of the "Orders" agent}

The "orders" agent defines the sequence of products to be manufactured in the presses. The agent is an infinite order queue where each order has the information of the product to be stamped and the quantity.

Production orders are generated continuously, keeping the presses operating at maximum capacity. Each production order generates a production list containing the quantity of each component to be stamped from the welded set to be manufactured. In the model considered, there are eight components to be stamped and their quantity will be proportional to the need for the manufacture of a welded set (Table 6).

Table 6. Component quantities in a production order.

\begin{tabular}{ccc}
\hline Types of Products & Product Quantity & Quantity per Order \\
\hline Stamped component 1 & 1 & 500 \\
\hline Stamped component 2 & 2 & 1000 \\
\hline Stamped component 3 & 1 & 500 \\
\hline Stamped component 4 & 1 & 500 \\
\hline Stamped component 5 & 2 & 1000 \\
\hline Stamped component 6 & 3 & 1500 \\
\hline Stamped component 7 & 2 & 1000 \\
\hline Stamped component 8 & 1 & 500 \\
\hline Welded set & 1 & 500 \\
\hline
\end{tabular}

\subsubsection{Computational structure of the "Main" agent}

The "main" agent consists of the main application program in AnyLogic software that makes the requests of the other agents and defines the structure of inputs and outputs in the model simulation. The "main" agent of the stamping modelling application is formed by the following agents:

- Four "press" agents that operate independently in parallel, stamping the components;

- Eight "tool" agents used respectively for each type of stamped component; 
- A "tooling" agent that performs the tool preparation and adjustment services on the press;

- Two "solder" agents that operate independently in parallel, welding the sets;

- A "maintenance" agent that performs the maintenance services on the presses and weld cells;

- An unlimited list of "orders" agents, which are the production orders generated continuously by the system.

In addition to the agents, the "main" agent is composed of dynamic lists of requests:

- Production order requests;

- Requests for tool preparation in the press;

- Requests for tool removal from the press;

- Requests for adjustments of the press tool for the tooling;

- Preventive maintenance requests from the tool to the tooling.

- Requests to repair the press for maintenance;

- Requests for preventive maintenance of the press;

- Welding cell repair requests for maintenance;

- Requests for preventive maintenance of the weld cell;

- Intermediate stock of stamped parts grouped by component.

\subsection{Advanced manufacturing}

The advanced manufacturing model is composed of the same agents as are defined in the conventional manufacturing model and simulated in the AnyLogic software, with the agents "press", "tool", "tooling", "weld", "maintenance", "orders", and "main" containing changes that reflect the implementation of advanced manufacturing systems such as the loT and CPSs previously defined.

\subsubsection{Computational Model of the "Advanced Press" Agent}

Two functionalities to the "advanced press" agent to improve the performance of the presses. The state diagram in the model is shown in Figure 18.

The first functionality inserted in the process consists of the "operac" state when the press is performing the stamping operation. There are two working conditions within the state, the first being "normal", when the product is within quality tolerances, and the second being "attention", when the product is within tolerances but, through sensors installed on the tool and in the press, it is detected that a tendency toward deviation is occurring. In the state of attention, through feedback control systems, the press makes automatic adjustments during operation without the need for or knowledge of the operator. In certain situations, the control cannot be restored properly and changes to the "adjustments" state with the request for intervention by the tooling services. 


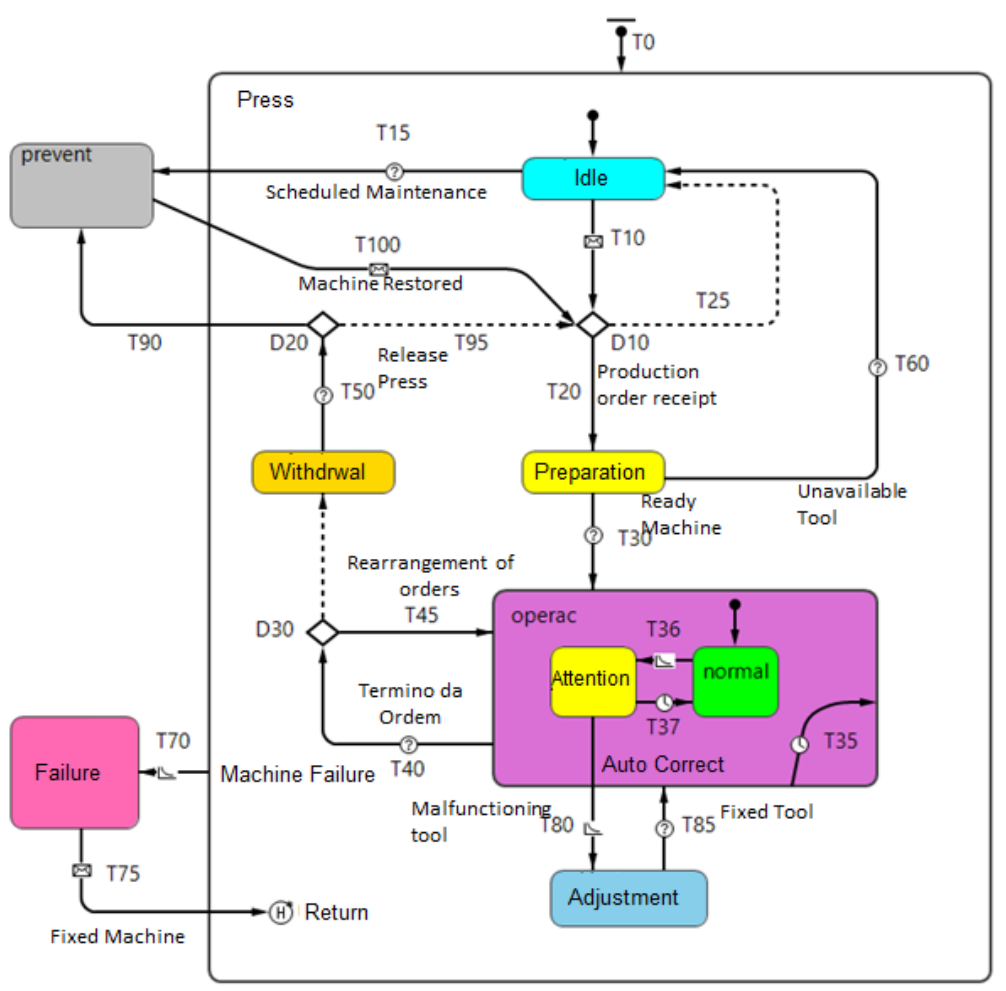

Figure 18 - State diagram of the "advanced press" agent.

The second functionality inserted consists of the advanced production planning system that monitors the production of the presses and evaluates the next production orders. It looks within the planning for the orders that are possible to anticipate, which are the orders for the same product that the press has finished producing. As a result, it is no longer necessary to change the tool, reducing machine downtime. In the state diagram in Figure 12, these features are represented by decision point D30 and transition $\mathrm{T} 45$.

The features described follow the $5 \mathrm{C}$ architecture of Lee et al. (2015), as part of the implementations to reach the five levels of implementation, comprising the connection of sensors to the network (level I), the conversion into information (level II), moving to the virtual model (level III), analysis and decision making (level IV), and self-adjustment (level V).

The "advanced press" agent incorporates the following parameters defined in Table 7.

Table 7. "Advanced press" parameters.

\begin{tabular}{ccc}
\hline Parameter & Transition & Value \\
\hline Rate of deviations from normal to attention state & T36 & 1 deviation/hour \\
\hline $\begin{array}{c}\text { Automatic adjustment time and return from attention to } \\
\text { normal state }\end{array}$ & T37 & $\begin{array}{c}\text { 2 minutes } \\
\text { (4 cycles of the press) }\end{array}$ \\
\hline Rate of deviation from attention to intervention & T80 & 4 deviations/day \\
\hline
\end{tabular}




\subsubsection{Computational model of the "Advanced Weld" agent}

The "advanced weld" agent was modified increase its performance. It is represented in the state diagram in Figure 19.

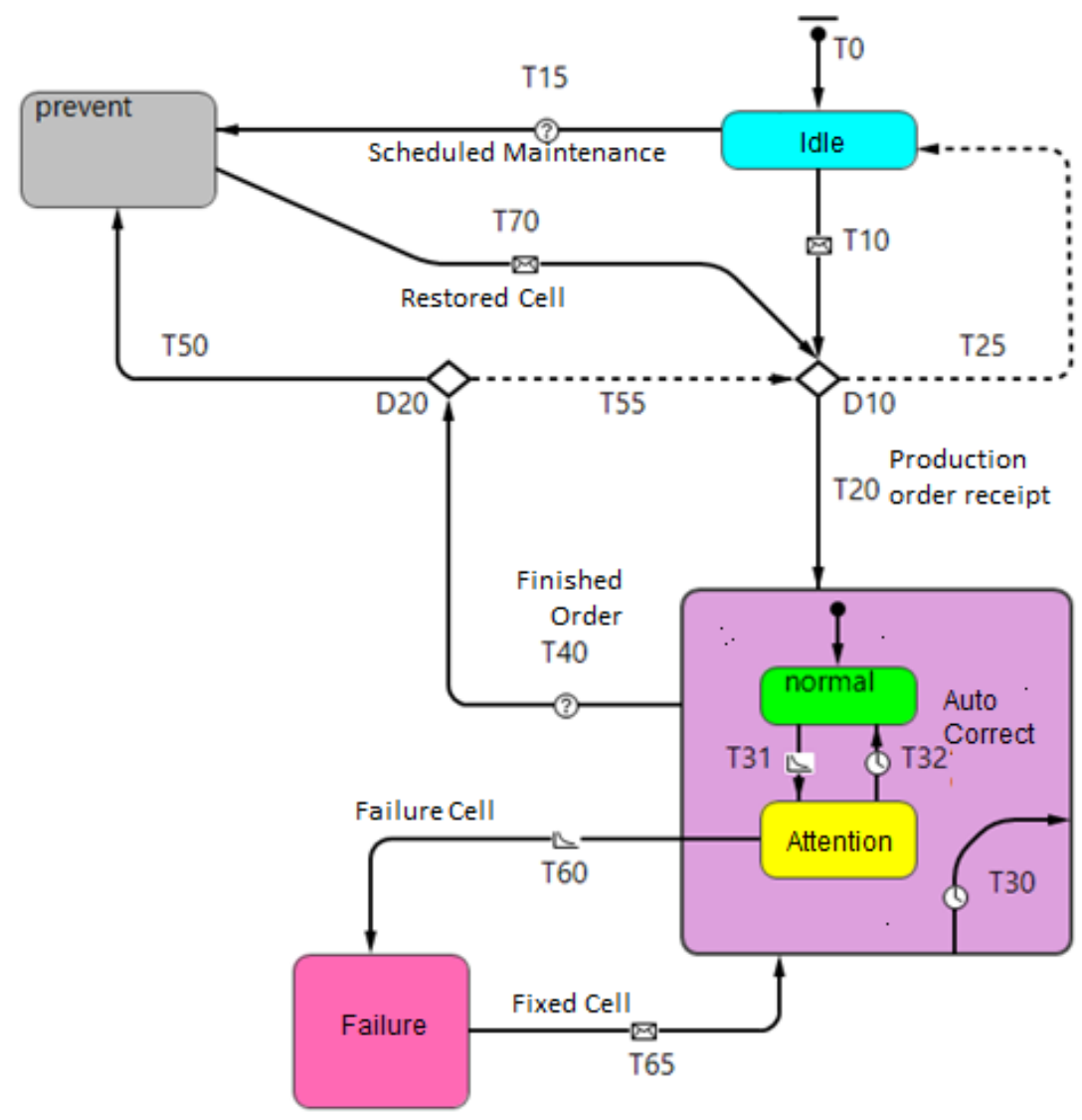

Figure 19. State diagram of the "advanced weld" agent.

In the operating state of the welding cell, represented by "weld", the states of "normal" operating conditions are inserted when the cell is producing in perfect working conditions. In the "attention" condition, there is a situation in which, through sensors and a control system, it is detected that some parameter of the weld cell has left its ideal operating point, such as the weld quality, robot trajectory, or position of parts, among others conditions that can be monitored. In this condition, the control system takes over the adjustments and seeks to restore the ideal working condition automatically. There may be situations in which the system is unable to achieve this condition and thus triggers a request for intervention by maintenance services. These situations are represented in the diagram in Figure 13 by the transitions T31 and T32 for automatic repair and T60 for maintenance intervention.

Like the "advanced press" agent, implementations follow the $5 \mathrm{C}$ architecture of Lee et al. (2015) to meet CPS levels.

The "advanced weld" agent incorporates the following parameters defined in Table 8. 
Table 8. "Advanced weld" parameters.

\begin{tabular}{ccc}
\hline Parameter & Transition & Value \\
\hline Rate of deviations from normal to attention state & T31 & 1 deviation/hour \\
\hline $\begin{array}{c}\text { Automatic repair time and return from attention to } \\
\text { normal state }\end{array}$ & T32 & $\begin{array}{c}\text { 8 minutes } \\
\text { (4 welding cycles) }\end{array}$ \\
\hline Failure rate: attention to intervention & T60 & 6 interventions/day \\
\hline
\end{tabular}

\section{Chosen simulation results}

The models presented above representing the manufacture of welded sets were simulated using AnyLogic software for a period of approximately two years (equivalent to 700 days in the simulation time), so that there was a relevant amount of data for preventive maintenance interventions to be considered in the results.

\subsection{Conventional manufacturing results}

Considering the agent-based simulation of the conventional manufacturing model, Figure 20 shows the level of use of the presses based on the percentage of time spent in each state of the "press" agent. The states are classified into six categories: idle, in operation, stopped for preparation, stopped for adjustments, stopped for corrective maintenance, and stopped for preventive maintenance.

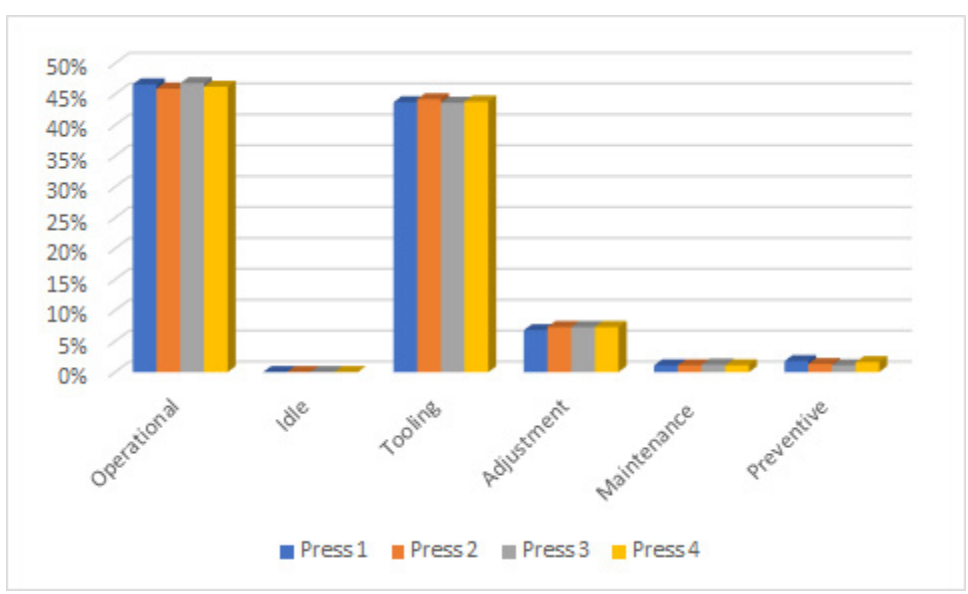

Figure 20. Level of use of the presses.

The results of the agent-based simulation indicate that the presses operate effectively for $46 \%$ of the total time. The time required for the preparation and removal of tools of the presses is about $44 \%$ of the total time. The index of adjustments for tool correction in the operation is around $7 \%$ and the corrective and preventive maintenance of the press takes around $2.6 \%$ of the total time.

In agent-based simulation, welding cells have a level of utilization of around $56 \%$ of the total time, with an idle rate of around 33\%, as shown in Figure 21 . The level of corrective maintenance interventions plus preventive maintenance is around $8.5 \%$. 


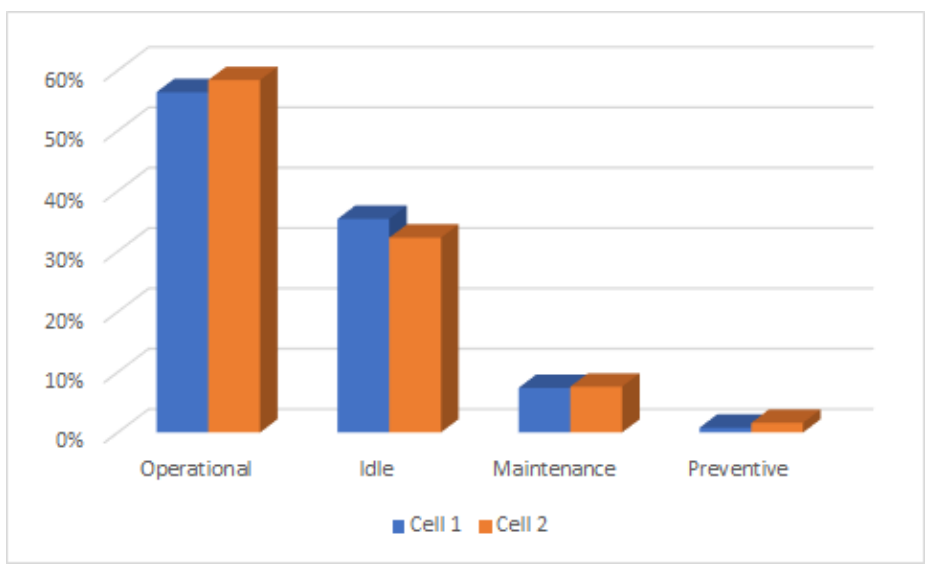

Figure 21. Level of use of the welding cells.

From the simulation, Figure 22 shows the results of tooling and maintenance allocation within their service assignments. The graphs present in more detail each function performed by the areas.
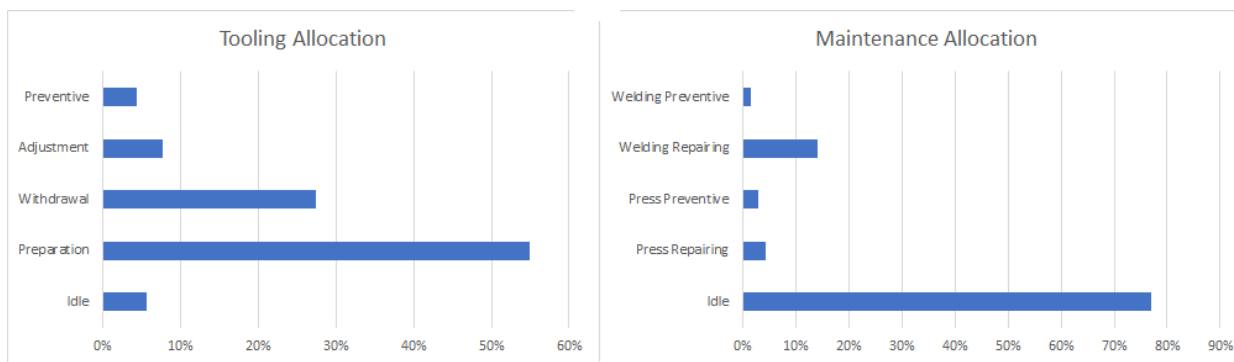

Figure 22. Service allocation.

The production volumes obtained from the operation of the presses and the robotic cells are represented by the graphs in Figure 23. The values are daily production averages, with around 10,500 pieces per day being produced by the presses and about 800 welded sets being produced per day.
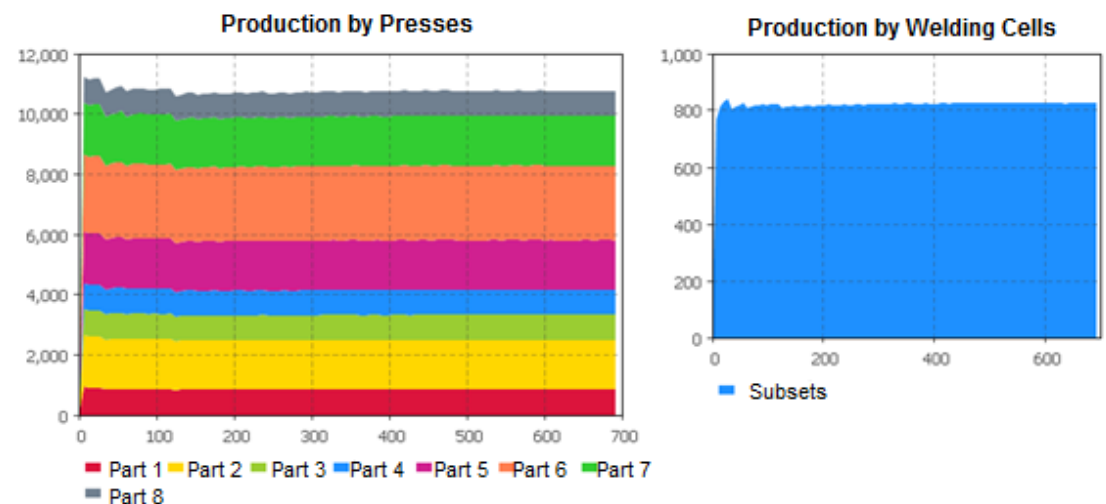

Figure 23. Daily production levels. 
The results of the simulations demonstrate the zero level of idleness of the presses as there is constant availability of material at the beginning of the line. However, the downtime due to tool preparation is very significant. On the other hand, the level of idleness of the welding cells is around $30 \%$ while waiting for products to be welded, which indicates that the stamping area is the bottleneck within the production flow of welded sets.

\subsection{Advanced manufacturing results}

The advanced manufacturing model is simulated by the agent-based simulation method in the AnyLogic software and the results are obtained with the simulation performed for an equivalent simulated period of two years (700 days). Figure 24 shows the level of use of the presses from the percentage of time spent in each state of the "advanced press" agent.

The utilization results indicate a significant improvement in the productivity of the presses, going from $46 \%$ utilization of the total time in conventional manufacturing to $76 \%$ in advanced manufacturing. This is mainly due to the reduction in the time required for the preparation and removal of tools of the presses, which changed from 44 to $21 \%$ of the total time. It also highlights the adjustment index for tool correction in the operation, which fell from $7 \%$ to less than $1 \%$.

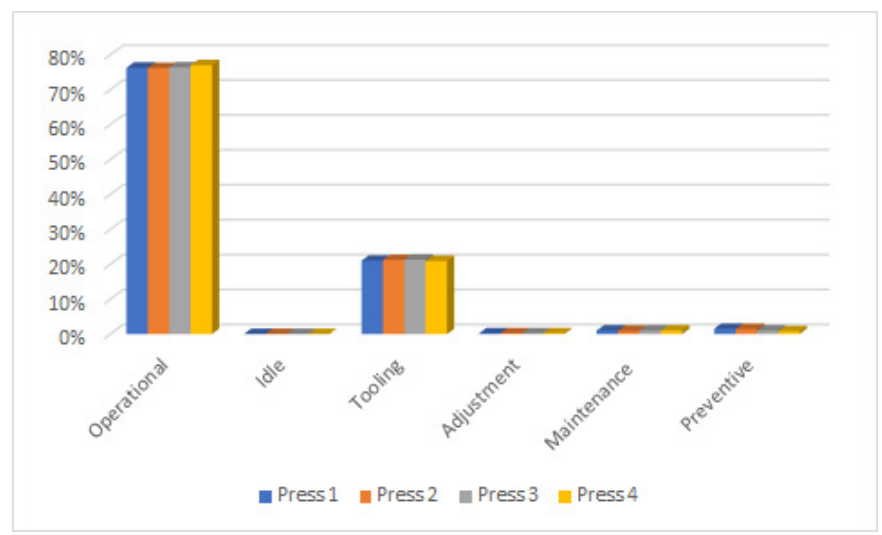

Figure 24. Utilization level of the "advanced presses".

The allocation of tooling services has consequently changed its behaviour with the reduction in the preparation of tools and their removal from presses. Figure 25 shows the tooling service allocation graph. The graph shows that the allocation for the services of preparation of tools and their and removal from the presses fell from $80 \%$ to around $55 \%$ of the total time and the idle time, previously almost nil, increased to $39 \%$. This is due to the lower number of tool changes in the presses due to the optimization of the tool use with real-time production order/reorder systems. As a result, the tooling industry has idle time that can be used for other functions not shown in this model. 


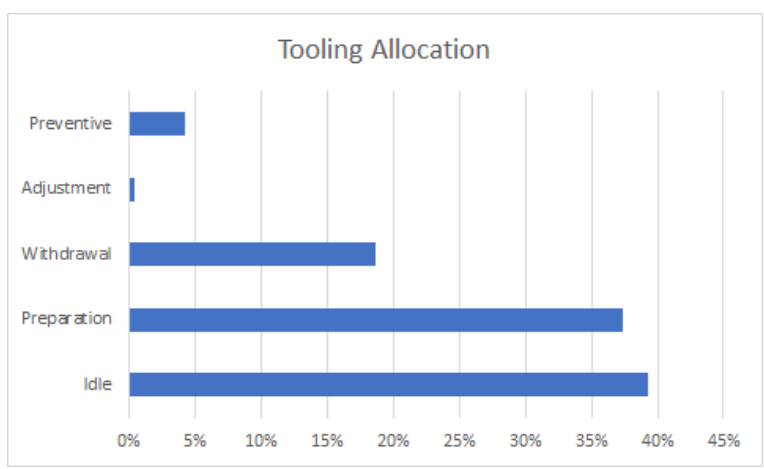

Figure 25. Tooling services.

The welding cells, with the change in the automatic fault monitoring and control system, went from a repair rate of $8 \%$ to about $1.5 \%$, making the cells more reliable. The operating rate increased to $94 \%$ with the increase in production of the presses, filling the idle times observed in the simulation of conventional manufacturing. The graphs in Figure 26 present these data obtained from the simulation.

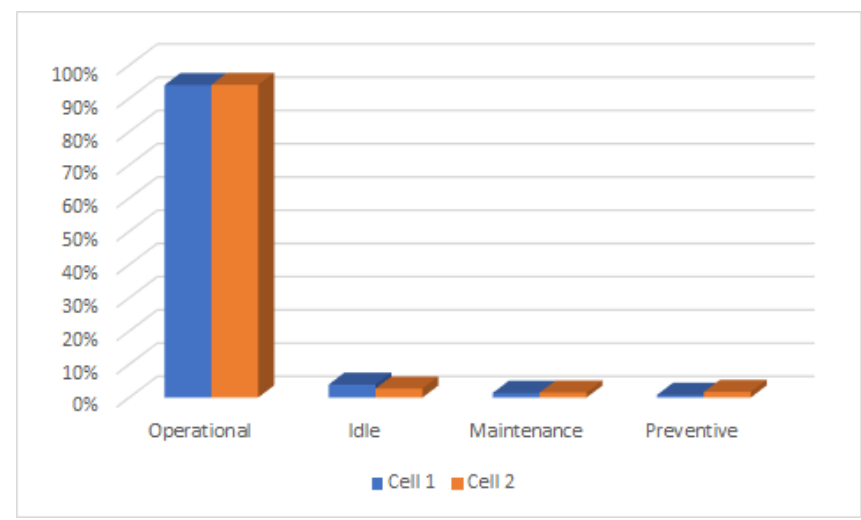

Figure 26. Advanced welding cells states.

With the reduction of maintenance service time in the welding cells, the maintenance service allocation graph (Figure 27) shows that there was a reduction in the time allocated for repair in the welding cell from $14 \%$ to less than $3 \%$ of the total time.

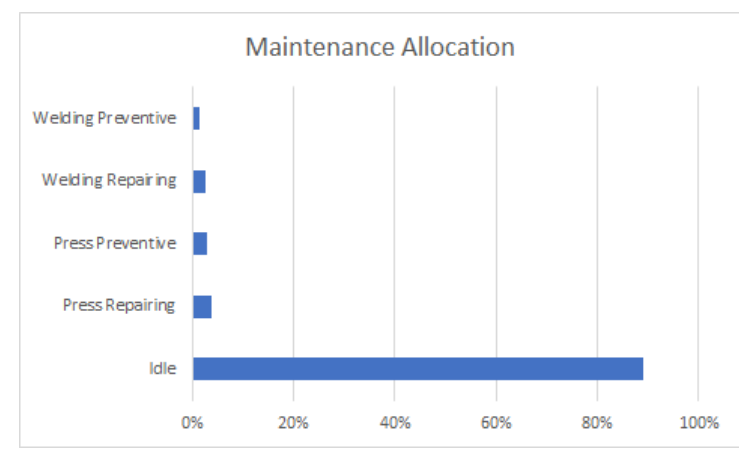

Figure 27. Maintenance allocation. 
Production volumes also experienced significant increases with the improvement of performance in the areas. The graphs in Figure 28 present this fact. The daily production values went from 10,500 pieces per day to about 18,000 pieces per day in the presses and the volume of welded sets went from 800 to about 1,400 sets per day at the exit of the welding cells.

The results reflect small changes related to three items identified as the most significant: production planning, tooling services, and maintenance services. In production planning, the press dynamically changes the production order plan to optimize the use of the installed tool. In tooling services, the system automatically adjusts the tool without stopping production. In maintenance services, the system automatically corrects faults without stopping production. The simulation results of these changes demonstrate a great impact on production levels.

The results of the simulated model show that the production reached a level of improvement of performance that led to a more balanced situation of the production resources.

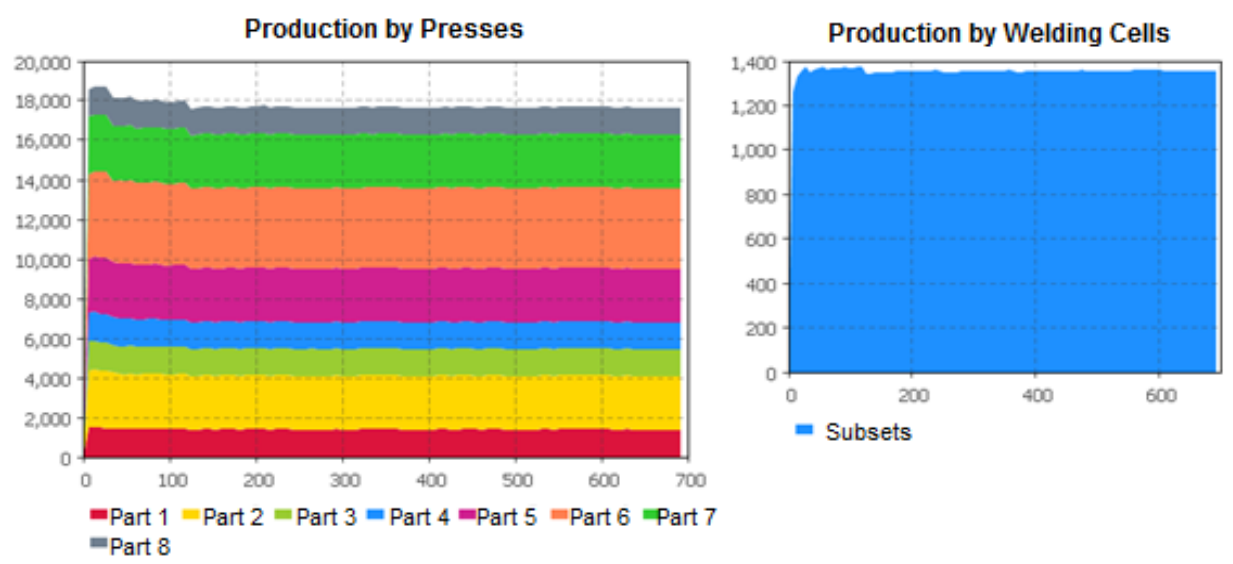

Figure 28. Daily production levels.

\section{Discussion of results}

From the results obtained with the agent simulation, it is possible to analyse the impacts of the insertion of the CPS, IOT, and Al in conventional manufacturing. To facilitate the discussion, the results of each agent have been graphically compiled and are presented in the following.

\subsection{Comparison of the presses}

Figure 29 shows a comparison of the different states of operation of the presses, considering the conventional manufacturing and the advanced manufacturing.

The results of the simulation of conventional manufacturing based on agents indicate that the presses operate effectively for $46 \%$ of the total time. The time required for the preparation of tools and their removal from the presses is about $44 \%$ of the total time. The index of adjustments for tool correction in operation is around $7 \%$, and the corrective and preventive maintenance of the press takes around $2.6 \%$ of the total time. 


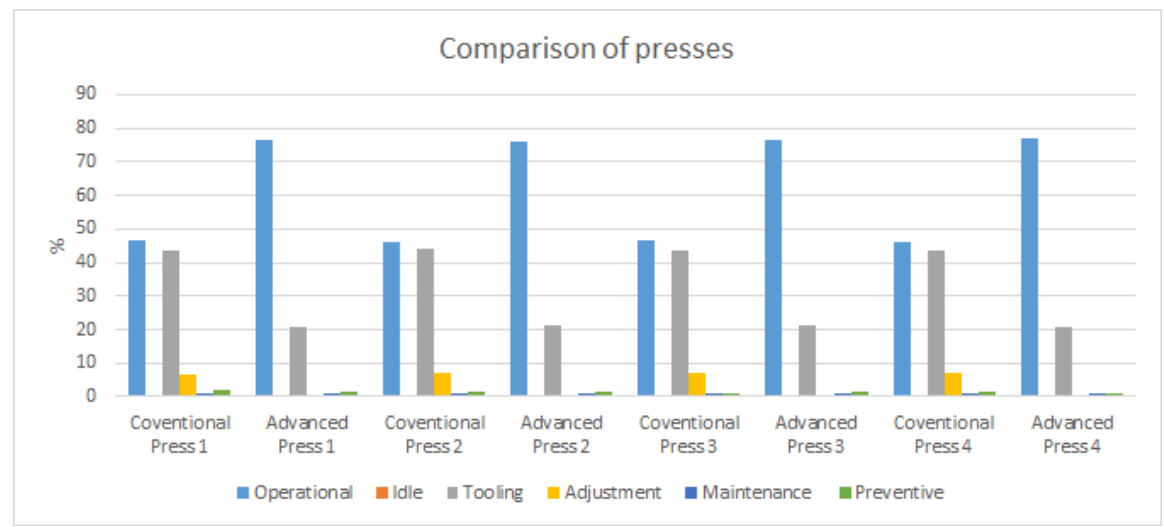

Figure 29. Comparison of different simulation results of the presses.

The results of advanced manufacturing indicate a significant improvement in the productivity of the presses, which went from $46 \%$ in conventional manufacturing to $76 \%$ in the utilization of the total time. This is mainly due to the reduction in the time required for the preparation of tools and their removal from the presses, which went from $44 \%$ to $21 \%$ of the total time. It also highlights the adjustment index for tool correction in the operation, which fell from $7 \%$ to less than $1 \%$.

The results of advanced manufacturing reflect the two improvements made to the "advanced press" agent. The first is purely technological and the second is managerial. The insertion of sensors in the tool and in the machine itself allows automatic adjustments that prevent the machine from stopping. On the other hand, reorganizing production orders reduces the amount of tool changes.

\subsection{Comparison of the welding cells}

Figure 30 shows a comparison of the different states of operation of the welding cells considering the conventional manufacturing and the advanced manufacturing.

In the simulation, conventional welding cells have a level of utilization of around $56 \%$ of the total time with an idle rate of about $33 \%$. The level of corrective maintenance interventions plus preventive maintenance is about $8.5 \%$.

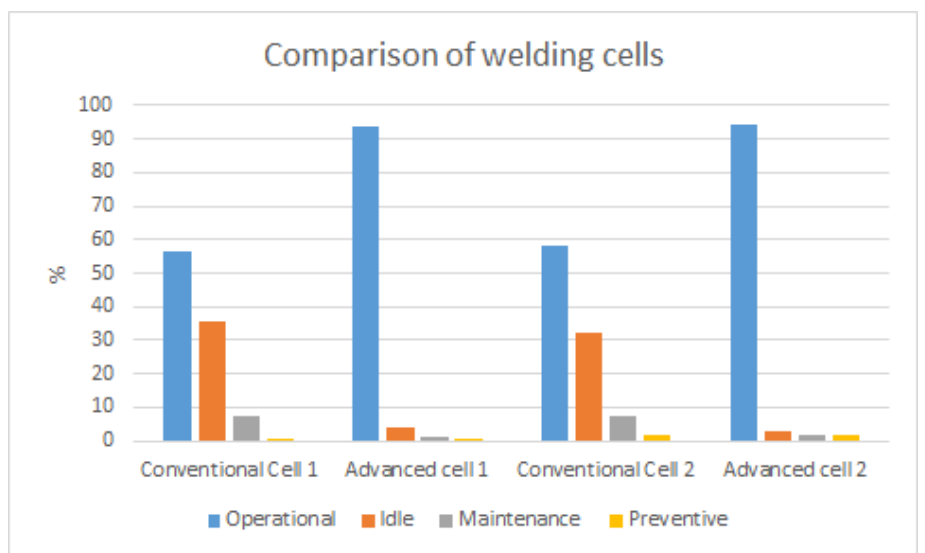

Figure 30. Comparison of different simulation results for the welding cells. 
The results for the welding cells reveal an increase in the operational state of the cells (with a consequent reduction in idleness), going from $57 \%$ on average in the conventional configuration to $94 \%$ on average in the advanced configuration. Moreover, the repair rate decreases from $8 \%$ to about $1.5 \%$, making the cells more reliable. In the same way as for the presses, the detection of operational deviations from sensors installed in the cells and the recovery from operational deviations justify the results. These results also highlight that the welding stage occurs after the operation of the presses, also showing a performance improvement with the sensing.

\subsection{Comparison of tooling services}

Figure 31 shows the comparison of the different states encompassed by the tooling service considering conventional and advanced manufacturing.

The first analysis refers to the idle state of the tooling service. Once both the presses and the welding cells are monitored and can adjust automatically and return to the normal state of operation, the tooling service requests decrease, significantly increasing the idle state.

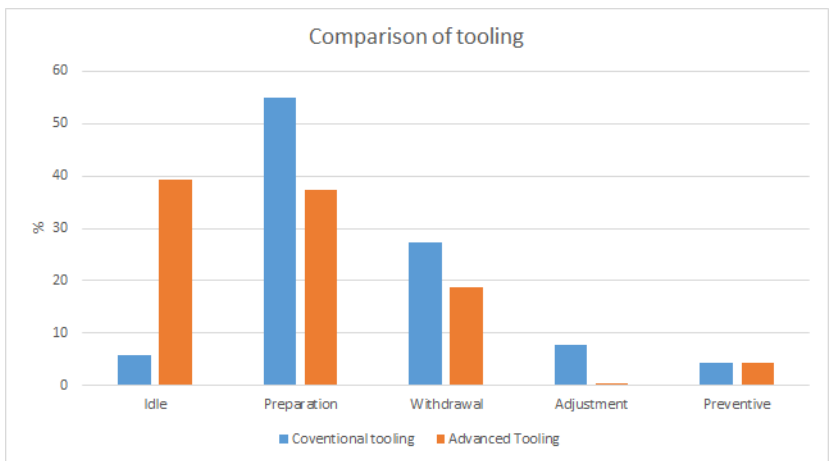

Figure 31. Comparison of different simulation results for the tooling service.

The graph shows that the allocation for the services of tool preparation and their removal from the presses fell from $80 \%$ to around $55 \%$ of the total time, while the idle time, previously almost nil, increased to $39 \%$. This is due to the lower number of tool changes required in the presses due to the optimization of the tool use with real-time production order/reorder systems. As a result, the tooling service has idle time that can be used for other functions not shown in this model. With adjustments being made automatically, the need for adjustments required by the tooling service is practically nil. The preventive part of the service does not change, since it is a scheduled event.

\subsection{Comparison of maintenance services}

Figure 32 shows the comparison of the different states encompassed by the maintenance service considering conventional and advanced manufacturing. 


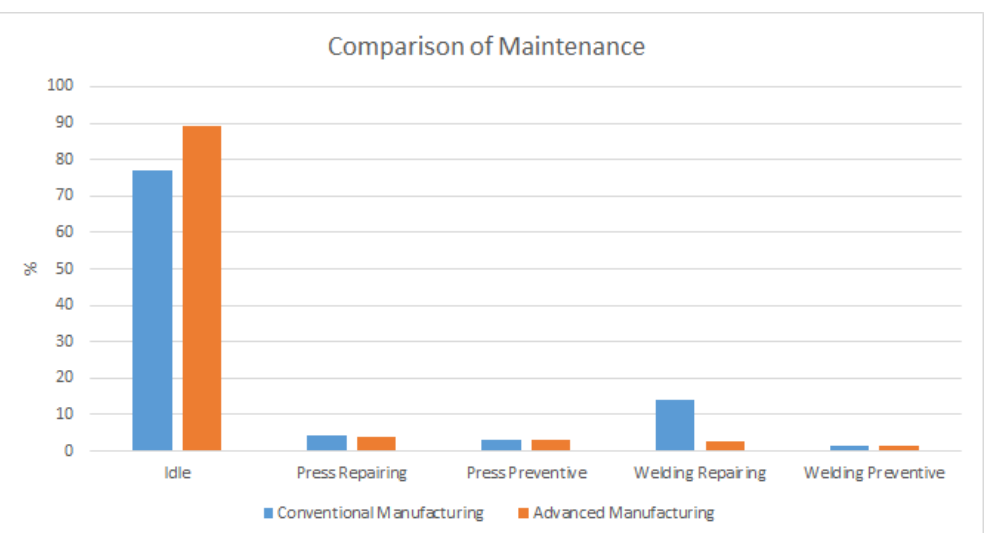

Figure 32. Comparison of different simulation results for the maintenance service.

The percentage idle time also increased for maintenance. This is a direct reflection of the automatic corrections implanted in the presses and in the welding stations, which led to a decrease in calls for corrective maintenance.

\subsection{Production}

\subsubsection{Conventional manufacturing}

The values are daily production averages and are around 10,500 pieces per day in the presses and about 800 welded sets per day.

The results of the simulations demonstrate the zero level of idleness of the presses as there is constant availability of material at the beginning of the line. However, the downtime due to tool preparation is very significant. On the other hand, the level of idleness of the welding cells is around $30 \%$ while waiting for products to be welded, which indicates that the stamping area is the bottleneck within the production flow of welded sets.

\subsubsection{Advanced manufacturing}

The daily production values went from 10,500 pieces per day to almost 18,000 pieces per day in the presses and the volume of welded sets went from 800 to almost 1,400 sets per day at the exit of the weld cells.

The results reflect small changes related to three items identified as the most significant: production planning, tooling services, and maintenance services. In production planning, the press dynamically changes the production order plan to optimize the use of the installed tooling. In tooling services, the system automatically adjusts the tool without stopping production. In maintenance services, the system automatically corrects faults without stopping production. The simulation results of these changes demonstrate a great impact on production levels.

The results of the simulation model show that the production reached a level of improvement of the performance that achieved a more balanced situation of the production resources. 


\section{Conclusion}

The modelling and simulation of a typical production line of welded subsets was used as a basis for comparison between the organization of a conventional line and the organization of a line using the concepts of advanced manufacturing. The agents, representing processes inherent in the production process, were able to better organize their activities in order to better use the resources through sensor data. Conventional line agents, while representing the same processes, maintained the previously defined organization and the respective activity and maintenance times. The differences between the final organization of the agents, respecting the order of the activities of the production process but changing the times according to the data from the sensors, allowed a new distribution of times, which significantly increased the quantity of products produced.

The simulations of conventional manufacturing and advanced manufacturing using agent-based modelling methods demonstrate differences in behaviour by changing the results shown by production indicators. These differences highlight the benefits of increased productivity that advanced manufacturing provides with the implementation of some process changes based on sensor data and the flexibility of decision making in which state a certain equipment must be.

The results of this study indicate possibilities for optimizing production lines with the application of artificial intelligence algorithms in the decision making of agents. Such algorithms can use data from sensors and production data to identify the organization of activities that maximize the production of a given set of products (such as those simulated in this work).

The present work contributes academically to the subject of Industry 4.0 since it is known from the literature that this new autonomous industrial system must behave as an MAS. Moreover, it can be said that the work contributes to the engagement of small and medium-sized companies in the adoption of these concepts of Industry 4.0 since they do not see clearly what benefits this new model can bring to their business. A limitation of the work is the absence of practical results since it is a modelling and simulation approach. The implementation of this theoretical proposal is a suggestion for future work.

\section{References}

Academia Nacional de Ciência e Engenharia - Acatech. (2013). Recommendations for implementing the strategic initiative INDUSTRIE 4.0 (pp. 1-78). Alemanha: Acatech.

Adeyeri, M. K., Mpofu, K., \& Adenuga, O. T. (2015). Integration of agent technology into manufacturing enterprise: a review and platform for Industry 4.0. In Proceedings of the International Conference on Industrial Engineering and Operations Management (pp. 1-10). http://dx.doi.org/10.1109/IEOM.2015.7093910.

Alsina, E. F., Cabri, G., \& Regattieri, A. (2014). An agent-based approach to simulate production, degradation, repair, replacement and preventive maintenance of manufacturing systems. In Proceedings of the 2014 IEEE Symposium on Computational Intelligence in Production and Logistics Systems (CIPLS) (pp. 24-31). http://dx.doi.org/10.1109/CIPLS.2014.7007157.

Balaji, P. G., \& Srinivasan, D. (2010). An introduction to multi-agent systems. In D. Srinivasan \& L. C. Jain (Eds.), Innovations in multi-agent systems and applications - 1 (Chap. 1, pp. 127). Berlin: Springer. http://dx.doi.org/10.1007/978-3-642-14435-6_1. 
Borshchev, A. (2014). The big book of simulation modeling - multimethod modeling with AnyLogic 6. USA: AnyLogic North America.

Büth, L., Broderius, N., Herrmann, C., \& Thiede, S. (2017). Introducing agent-based simulation of manufacturing systems to industrial discrete-event simulation tools. In Proceedings of the IEEE 15th International Conference on Industrial Informatics (INDIN) (pp. 1141-1146). USA: IEEE.

Dafflon, B., Essamlali, M. T. E., Sekhari, A., \& Bouras, A. (2016). A reactive agent-based decision-making system for SBCE. In Proceedings of the IEEE 28th International Conference on Tools with Artificial Intelligence (ICTAI) (pp. 746-753). USA: IEEE.

Feng, Y., \& Fan, W. (2014). A hybrid simulation approach to dynamic multi-skilled workforce planning of production line. In Proceedings of the Winter Simulation Conference (pp. 16321643). USA: IEEE. http://dx.doi.org/10.1109/WSC.2014.7020014.

Hermann, M., Pentek, T., \& Otto, B. (2016). Design principles for Industrie 4.0 scenarios. In Proceedings of the 49th Hawaii International Conference on System Sciences (pp. 39283937). USA: IEEE. http://dx.doi.org/10.1109/HICSS.2016.488.

Industrial Internet Consortium - IIC. (2015). Industrial internet reference architecture (pp. 1101). USA: Industrial Internet Consortium.

Jules, G., \& Saadat, M. (2017). Agent cooperation mechanism for decentralized manufacturing scheduling. IEEE Transactions on Systems, Man, and Cybernetics. Systems, 47(12), 33513362. http://dx.doi.org/10.1109/TSMC.2016.2578879.

Kadera, P., \& Novák, P. (2015). Automatic compilation of performance models for industrial Multi-Agent Systems. In Proceedings of the IEEE 20th Conference on Emerging Technologies \& Factory Automation (ETFA) (pp. 1-8). USA: IEEE.

Kang, H. S., Lee, J. Y., Choi, S., Kim, H., Park, J. H., Son, J. Y., Kim, B. H., \& Noh, S. D. (2016). Smart manufacturing: past research, present findings, and future directions. International Journal of Precision Engineering and Manufacturing Green Technology, 3(1), 111-128. http://dx.doi.org/10.1007/s40684-016-0015-5.

Lee, J., Bagheri, B., \& Kao, H.-A. (2015). Cyber-physical systems architecture for Industry 4.0based manufacturing systems. Manufacturing Letters, 3, 18-23. http://dx.doi.org/10.1016/j.mfglet.2014.12.001.

Leitão, P., Karnouskos, S., Ribeiro, L., Lee, J., Strasser, T., \& Colombo, A. W. (2016). Smart agents in industrial cyber-physical systems. Proceedings of the IEEE, 104(5), 1086-1101. http://dx.doi.org/10.1109/JPROC.2016.2521931.

Leitão, P., Marík, V., \& Vrba, P. (2013). Past, present, and future of industrial agent applications. IEEE Transactions on Industrial Informatics, 9(4), 2360-2372. http://dx.doi.org/10.1109/TII.2012.2222034.

Metzger, M., \& Polaków, G. A. (2011). A survey on applications of agent technology in industrial process control. IEEE Transactions on Industrial Informatics, 7(4), 570-581. http://dx.doi.org/10.1109/TII.2011.2166781.

Novak, P., Kadera, P., \& Wimmer, M. (2018). Agent-based modeling and simulation of hybrid cyber-physical systems. In Proceedings of the 3rd IEEE International Conference on Cybernetics (CYBCONF) (pp. 1-8). USA: IEEE.

Scholz, M., Oberschachtsiek, S., Donhauser, T., \& Franke, J. (2017). Software-in-the-loop testbed for multi-agent-systems in a discrete event simulation: Integration of the Java agent development framework into plant simulation. In Proceedings of the IEEE International Systems Engineering Symposium (ISSE) (pp. 1-6). USA: IEEE. http://dx.doi.org/10.1109/SysEng.2017.8088320.

Schwab, K. (2016). The fourth industrial revolution. USA: World Economic Forum. 
Shpilevoy, V., Shishov, A., Skobelev, P., Kolbova, E., Kazanskaia, D., Shepilov, Y, \& Tsarev, A. (2013). Multi-agent system "Smart Factory" for real-time workshop management in aircraft jet engines production. IFAC Proceedings Volumes, 46(7), 204-209.

Trappey, A. J. C., Trappey, C. V., Govindarajan, U. H., Sun, J. J., \& Chuang, A. C. (2016). A review of technology standards and patent portfolios for enabling cyber-physical systems in advanced manufacturing. IEEE Access : Practical Innovations, Open Solutions, 4, 73567382. http://dx.doi.org/10.1109/ACCESS.2016.2619360.

VDI/VDE. (2015). Reference architecture model industrie 4.0 (RAMI 4.0). Berlin: VDI/VDE.

Vrba, P., Tichý, P., Marík, V., Hall, K. H., Staron, R. J., Maturana, F. P., \& Kadera, P. (2011). Rockwell automation's holonic and multiagent control systems compendium. IEEE Transactions on Systems, Man, and Cybernetics, 41(1), 14-30. http://dx.doi.org/10.1109/TSMCC.2010.2055852. 